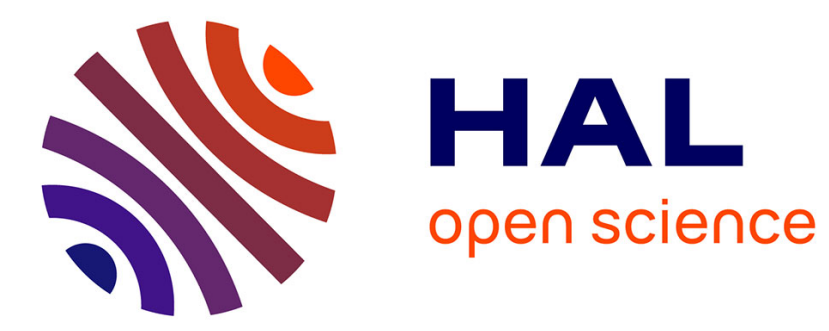

\title{
Stress evolution and associated microstructure during transient creep of olivine at $1000-1200^{\circ} \mathrm{C}$
}

\author{
Manuel Thieme, Sylvie Demouchy, D. Mainprice, F. Barou, P. Cordier
}

\section{To cite this version:}

Manuel Thieme, Sylvie Demouchy, D. Mainprice, F. Barou, P. Cordier. Stress evolution and associated microstructure during transient creep of olivine at $1000-1200{ }^{\circ} \mathrm{C}$. Physics of the Earth and Planetary Interiors, 2018, 278, pp.34-46. 10.1016/j.pepi.2018.03.002 . hal-01746122

\section{HAL Id: hal-01746122 \\ https://hal.science/hal-01746122}

Submitted on 29 Mar 2018

HAL is a multi-disciplinary open access archive for the deposit and dissemination of scientific research documents, whether they are published or not. The documents may come from teaching and research institutions in France or abroad, or from public or private research centers.
L'archive ouverte pluridisciplinaire HAL, est destinée au dépôt et à la diffusion de documents scientifiques de niveau recherche, publiés ou non, émanant des établissements d'enseignement et de recherche français ou étrangers, des laboratoires publics ou privés.

\section{(ㅇ)(1) $\$$}

Distributed under a Creative Commons Attribution - NonCommercial - NoDerivatives| 4.0 


\title{
Stress evolution and associated microstructure during transient creep of olivine at $1000-1200{ }^{\circ} \mathrm{C}$
}

\author{
M. Thieme ${ }^{1 *}$, S. Demouchy ${ }^{1}$, D. Mainprice ${ }^{1}$, F. Barou ${ }^{1}$, P. Cordier $^{2}$ \\ ${ }^{1}$ Geosciences Montpellier, CNRS \& Université de Montpellier, UMR5243, 34095 Montpellier, France \\ ${ }^{2}$ Univ. Lille, CNRS, INRA, ENSCL, UMR 8207 - UMET - Unité Matériaux et Transformations, F-59000 Lille, France
}

* corresponding author

Manuel Thieme

Place Eugène Bataillon, Bat. 22

34095 Montpellier, FRANCE

Manuel.Thieme@gm.univ-montp2.fr

+33768472281

The published version of this paper can be found as:

Thieme, M.*, Demouchy, S., Mainprice, D., Barou, F., Cordier,. P. (2018) Stress evolution and associated microstructure during transient creep of olivine at $1000-1200^{\circ} \mathrm{C}$, Phys. Earth Planet. Int., doi:

10.1016/j.pepi.2018.03.002

Supplementary material can be found online or given after request. 


\section{Abstract}

We study the mechanical response and correlated microstructure of axial deformed fine-grained olivine aggregates as a function of incremental finite strains. Deformation experiments were conducted in uniaxial compression in an internally heated gas-medium deformation apparatus at temperatures of 1000 and $1200{ }^{\circ} \mathrm{C}$, at strain rates of $10^{-6} \mathrm{~s}^{-1}$ to $10^{-5} \mathrm{~s}^{-1}$ and at confining pressure of $300 \mathrm{MPa}$. Sample volumes are around $1.2 \mathrm{~cm}^{3}$. Finite strains range from 0.1 to $8.6 \%$ and corresponding maximal (final) differential stresses range from 80 to $1073 \mathrm{MPa}$ for deformation at $1000{ }^{\circ} \mathrm{C}$ and from 71 to $322 \mathrm{MPa}$ for deformation at $120{ }^{\circ} \mathrm{C}$. At $1200{ }^{\circ} \mathrm{C}$, samples approach steady state deformation after about $8 \%$ of strain. At $1000{ }^{\circ} \mathrm{C}$, significant strain hardening leads to stresses exceeding the confining pressure by a factor of 3.5 with brittle deformation after $3 \%$ of strain. Deformed samples were characterized by electron backscatter diffraction (EBSD) and transmission electron microscopy (TEM). EBSD maps with step sizes as low as $50 \mathrm{~nm}$ were acquired without introducing analytical artifacts for the first time. The grain size of deformed samples ranges from 2.1 to $2.6 \mu \mathrm{m}$. Despite clear strain hardening, texture or microstructure do not change as a function of stress or finite strain. This observation is supported by a constant texture strength (J-index) and symmetry (BA-index), constant grain shape and aspect ratio, constant density of geometrically necessary dislocations, grain orientation spread, and constant subgrain boundary spacing and misorientation in between samples. TEM shows that all samples exhibit unambiguous dislocation activity but with a highly heterogeneous dislocation distribution. Olivine grains display evidence of [100] and [001] slip activity, but there is no evidence of interaction between the dislocations from the different slip systems. Several observations of grain boundaries acting as dislocation sources have been found. We find no confirmation of increasing dislocation densities as the cause for strain hardening during transient creep. This suggests other, yet not fully understood mechanisms affecting the strength of deformed olivine. These mechanisms could possibly involve grain boundaries. Such mechanisms are relevant for the deformation of uppermost mantle rocks, where the $\mathrm{Si}$ diffusion rate is too slow and dislocation glide must be accommodated in another way to fulfill the von Mises criterion.

Keywords: plastic deformation; olivine; creep; dislocations; Earth lithosphere. 


\section{Introduction}

Olivine is the most abundant ( $>60 \%{ }_{\text {vol }}$ ) and the weakest mineral phase of Earth's upper mantle. As such, it largely controls the rheology of the upper mantle and in turn the contribution of mantle convection to the formation and motion of tectonic plates. Since the upper mantle encompasses rocks within a wide range of temperatures, its rheology has to be studied in an equally broad thermal range.

Early flow laws quantifying the rheology of olivine were mostly obtained from experiments at temperatures above $1200{ }^{\circ} \mathrm{C}$ (e.g. Chopra \& Paterson, 1984; Karato et al., 1986; Bai et al., 1991; Hirth \& Kohlstedt, 1995; Mei \& Kohlstedt, 2000a, 2000b; Faul et al. 2011; Keefner et al., 2011; Tielke et al., 2017) to avoid to reach the brittle field. Experiments performed at temperatures relevant to the uppermost lithospheric mantle ( $\leq 1000{ }^{\circ} \mathrm{C}$, e.g. Evans \& Goetze, 1979; Raterron et al., 2004; Demouchy et al. 2009, 2013, 2014; Mei et al., 2010; Idrissi et al., 2016; Tielke et al., 2016) report a lower strength of olivine than was expected from extrapolation of high-temperature flow laws. The low temperature plasticity is a key to understanding deformation of the shallow upper mantle (Hirth \& Kohlstedt, 1995) but also in subducting slabs (Goetze \& Evans, 1979; Kirby, 1980; Karato et al., 2001), where it governs the stress storage capacity and therefore the maximal stress release of deep earthquakes (e.g., Proietti, 2016).

Until recently, the deformation and microstructure of olivine were characterized under a so-called mechanical steady state, when stress becomes constant and independent of plastic strain. Therefore, the mechanical response and evolution of microstructure before reaching steady state (i.e., transient creep) is largely not understood. The initial rapid increase in stress is traditionally attributed to an increase in the dislocation density, which is reported to become constant in single crystals after about $2 \%$ of strain (e.g., Durham et al., 1977). Even under constant dislocation densities, the dislocation structures continue to evolve and reaching a constant dislocation structure requires a finite amount of strain. Transient creep at temperatures and pressures relevant for the lithospheric mantle might prove crucial to understanding the initiation and localization of deformation processes that impact lithospheric plate generation and motion.

The main deformation mechanisms of olivine are 1) glide and climb of dislocations in the crystal lattice, typically called dislocation creep 2) diffusion of atoms and vacancies at temperatures above approximately $1200{ }^{\circ} \mathrm{C}$, which is grain size sensitive (i.e., diffusion creep) and 3) grain boundary controlled mechanisms, such as grain boundary migration or grain boundary sliding. The dominant deformation mechanism depends on the stress, temperature, grain size, strain rate, the crystal chemistry, the oxygen fugacity, partial melt content and even the trace amount of hydrogen (e.g. Carter \& Lallemand, 1970; Chopra \& Paterson, 1981, 1984; Mackwell et al., 1985; Cooper \& Kohlstedt, 1984, 1986; Bai et al., 1991; Bai \& Kohlstedt, 1992; Mei \& Kohlstedt, 2000 a,b; Hirth \& Kohlstedt, 1995, 2003; Warren \& Hirth, 2006; Mackwell, 2008; Faul et al., 2011, 2016; Keefner et al., 2011; Demouchy et al., 2012; Tielke et al., 2016, 2017). Dislocation glide is thought to be the dominant deformation mechanism at low temperatures $(<1200$ ${ }^{\circ} \mathrm{C}$ in $\mathrm{Fo}_{90}$ ) and for grain sizes $>1 \mathrm{~mm}$ prevalent in mantle olivine, since $\mathrm{Si}$ is the slowest diffusing species in silicates and its diffusivity is highly dependent on temperature (Chakraborty, 2010). Yet, dislocations in olivine can only glide in three independent slip systems $([100](010), \quad[100](001),[001](010)$ or $[100](010)$, [001](010), [001](100)). In the case of inhomogeneous flow (i.e., flow in polycrystals), at least four independent slip systems must operate to satisfy the von Mises criterion (Mises, 1928; Hutchinson, 1977). Therefore, the currently known dislocation slip systems in olivine are not enough, and additional degrees of freedom must be provided by e.g. dislocation climb, grain boundary sliding or grain boundary migration triggered by disclinations. Disclinations (rotational topological defects) were known to exist in liquid crystals (Friedel, 1922; Frank, 1958) but were thought to be too energetically costly in crystalline solids. Nevertheless, they were recently described along the grain boundaries of copper and olivine (Beausir \& Fressengeas, 2013; Cordier et al. 2014).

The slip systems in which dislocations glide in olivine are well documented, and Turner (1942) already anticipated the principal glide system in naturally occurring olivine to be [100](010). Most of the early deformation experiments at high temperature targeting slip systems were conducted by Raleigh (1965, 1967, 1968), who concluded that the dominant slip system is dependent on the temperature and the strain rate: at $10^{-5} \mathrm{~s}^{-1}$, glide on [001](100) dominates at $<300{ }^{\circ} \mathrm{C},[001]\{110\}$ between 300 to $1000{ }^{\circ} \mathrm{C}$ and finally $[100]\{0 \mathrm{kl}\}$ at temperatures of $>1000{ }^{\circ} \mathrm{C}$ (see also Young, 1969). A comparison of microstructures in naturally and experimentally deformed peridotites by Nicolas (1986) confirmed that the same slip systems are active. Such a comparison holds true for mantle rock textures (e.g., Nicolas \& Poirier, 1976; Gueguen \& Nicolas, 1980; Tommasi et al., 1999, 2016).

First olivine flow laws were provided by Carter \& Avé-Lallemant (1970) for wet and dry dunites and Iherzolites, also observing dislocation climb controlled processes (polygonization) and recrystallization at temperatures of $1000{ }^{\circ} \mathrm{C}$ and $1050{ }^{\circ} \mathrm{C}$ respectively. 
Carter and Avé-Lallemant attributed a weakening effect to the presence of hydrogen in the structure of olivine, expressed by a reduced activation energy of dislocation creep (335 instead of $\left.502 \mathrm{~kJ} \cdot \mathrm{mol}^{-1}\right)$. Hirth \& Kohlstedt (1996), Mei \& Kohlstedt (2000 a,b), Demouchy et al. (2012, 2014), Fei et al. (2013), Girard et al. (2013) and Tielke et al. (2017) confirm a weakening effect by water, although the most recent results highlight that it might induce a relatively limited effect (i.e., viscosity diminution by only a factor of 10 for hydrous olivine viscosity at mantle strain rates, Tielke et al., 2017) for hydrogen concentrations reported in spinel-bearing peridotite typical of the lithospheric mantle (Demouchy and Bolfan-Casanova, 2016).

Based on high pressure deformation experiments, Karato and co-workers have proposed a classification in five types of olivine fabrics developing as a function of the applied stress and water content (Jung and Karato, 2001), but until now, the physical mechanism which could explain the crystallographic preferred orientations (CPO) variations is still lacking. Other studies recognized an effect of grain size on the strength of olivine (Goetze, 1978; Karato et al., 1986; Karato and Wu, 1993; Katayama et al., 2004). At smaller grain sizes (sub $\mu \mathrm{m}$ ), dislocations are increasingly captured by grain boundaries, resulting in only few organized sub grain boundaries. In such small grains, the rate-limiting factor is dislocation glide or ionic diffusion rates, as opposed to dislocation climb in larger grains and for higher finite strains (e.g., Hiraga et al., 2011 ; Miyazaki et al., 2013).

In this study, we perform a series of deformation experiments at high pressure and high temperature on fine-grained polycrystalline olivine aggregates at temperatures of $1000{ }^{\circ} \mathrm{C}$ and $1200{ }^{\circ} \mathrm{C}$. Experiments are stopped at increasing higher finite strains $(0$ to 8.6 $\%$, representing all stages of the stress-strain curve. The starting material and deformed samples are characterized by scanning electron microscopy (SEM), electron backscattered diffraction (EBSD) and transmission electron microscopy (TEM).

\section{Methods}

\subsection{Starting material and experimental method}

Olivine crystals from San Carlos (Arizona) with the following composition $\left(\mathrm{Mg}_{0.91} \mathrm{Fe}_{0.09} \mathrm{Ni}_{0.003}\right)_{2} \mathrm{SiO}_{4}$ (e.g., Buening \& Buseck, 1973; Frey \& Prinz, 1978) are used for the deformation experiments. The fine powder was obtained by grinding olivine crystals in a fluid energy mill (Gribb \& Cooper, 1998). San Carlos olivine naturally has extremely low water content of less than $1 \mathrm{ppm}$ wt $\mathrm{H}_{2} \mathrm{O}$ (Mackwell et al., 1985; Mei \& Kohlstedt, 2000a; Demouchy, 2010). Fine-grained powder of San Carlos olivine was cold-pressed and subsequently hotpressed in Ni sleeves at $1200{ }^{\circ} \mathrm{C}$ and $300 \mathrm{MPa}$ for 3 hours, producing dense polycrystalline samples $\sim 8$ $\mathrm{mm}$ in diameter and $\sim 16 \mathrm{~mm}$ long. The $\mathrm{Ni}$ sleeves were closed prior to hot-pressing with fitted $\mathrm{Ni}$ disks (200 $\mu \mathrm{m}$ thick), held in place by $\sim 2 \mu \mathrm{l}$ of externally applied superglue. The glue is dried out before insertion into the apparatus, volatized during hotpressing and does not induce hydrogen incorporation into the sample. Hot-pressing, as well as axial deformation was performed in a high-pressure hightemperature internally heated, in situ deformation apparatus (also called the Paterson Press; see Paterson, 1990) using Argon as pressure medium. This deformation apparatus allows a high resolution of the applied stress $( \pm 10 \mathrm{MPa})$ and minimal thermal gradient $\left( \pm 2{ }^{\circ} \mathrm{C}\right)$ along a hot zone of approximately 20 $\mathrm{mm}$ length (Paterson, 1990). Sample volumes of $\sim 1$ $\mathrm{cm}^{3}$ and diameter to length ratio of $1: 2$ reduce boundary effects on the texture evolution and stress distribution. Samples were deformed in axial compression at $300 \pm 2 \mathrm{MPa}$ confining pressure, for constant displacement rates $\left(1.25\right.$ to $1.70 \times 10^{-4} \mathrm{~mm} \mathrm{~s}^{-}$ $\left.{ }^{1}\right)$. Part of the displacement is taken up by elastic deformation of the apparatus. Consequently, the instantaneous strain rate of the sample changes as stress evolves during the experiment, reaching $10^{-5} \mathrm{~s}^{-1}$ at mechanical steady state conditions. Temperatures were kept constant during deformation. The $\mathrm{Ni}$ capsules containing the olivine samples were mounted with alumina and zirconia pistons inside an iron jacket (e.g., Paterson, 1990; Mei \& Kohlstedt, 2000a). The oxygen fugacity was theoretically controlled by the nickel capsule. However, in a recent experimental study, the $\mathrm{fO}_{2}$ in large sample volumes has been shown to decrease towards the sample center,

\begin{tabular}{|c|c|c|c|c|c|c|c|c|c|c|c|}
\hline & \multicolumn{6}{|c|}{ Deformation at $1000{ }^{\circ} \mathrm{C}$} & \multicolumn{5}{|c|}{ Deformation at $1200{ }^{\circ} \mathrm{C}$} \\
\hline & CMT16-6 & CMT16-2 & CMT16-4 & CMT16-8 & CMT17-4 & CMT17-2 & CMT17-1 & CMT16-12 & CMT16-15 & CMT16-13 & CMT16-9 \\
\hline Temperature $\left[{ }^{\circ} \mathrm{C}\right]$ & 1000 & 1000 & 1000 & 1000 & 1000 & 1000 & 1200 & 1200 & 1200 & 1200 & 1200 \\
\hline Duration [min] & 11 & 24 & 42 & 79 & 87 & 218 & 8 & 25 & 40 & 84 & 174 \\
\hline Initial length $\mathrm{L}_{0}[\mathrm{~mm}]$ & 13.50 & 16.45 & 16.10 & 12.53 & 17.15 & 13.75 & 16.95 & 16.90 & 16.94 & 15.82 & 16.96 \\
\hline Strain rate $\dot{\varepsilon}\left[\mathrm{s}^{-1}\right]$ & $1.9 \times 10^{-6}$ & $2.8 \times 10^{-6}$ & $3.4 \times 10^{-6}$ & $3.3 \times 10^{-6}$ & $5.8 \times 10^{-6}$ & $1.1 \times 10^{-5}$ & $4.0 \times 10^{-6}$ & $7.2 \times 10^{-6}$ & $7.8 \times 10^{-6}$ & $1.0 \times 10^{-5}$ & $1.0 \times 10^{-5}$ \\
\hline Finite strain $\varepsilon[\%]$ & 0.11 & 0.30 & 0.42 & 1.07 & 1.64 & 7.33 & 0.19 & 0.88 & 1.50 & 3.68 & 8.59 \\
\hline Diff stress $\sigma_{\max }[\mathrm{MPa}]$ & 80 & 258 & 440 & 684 & 787 & 1073 & 71 & 150 & 232 & 313 & 322 \\
\hline
\end{tabular}


resulting in a linear $\log \left(\mathrm{fO}_{2}\right) \approx-10$, at a distance $>0.5$ $\mathrm{mm}$ from the capsule interface (Faul et al., 2017, their fig 5.), which remains in line with common mantle rocks (Frost \& McCammon, 2008). Temperature was manually increased at a rate of approximately 10 ${ }^{\circ} \mathrm{C} / \mathrm{min}$ before using the automatic temperature controller. Quenching of the samples is achieved by a manually controled decrease of furnace power, reducing temperature by $100{ }^{\circ} \mathrm{C} / \mathrm{min}$. Faster cooling might induce severe damage to the furnace. A total of ten samples were deformed at temperatures of 1000 ${ }^{\circ} \mathrm{C}$ and $1180-1200{ }^{\circ} \mathrm{C}$. Experimental conditions are listed in Table 1.

To account for the load supported by the iron jacket and nickel sleeve, the flow laws reported by Frost and Ashby (1982) were used, following a wellestablished procedure (Mei \& Kohlstedt, 2000a; Chen et al., 2006; Demouchy et al., 2009; Hansen et al., $2011,2012)$. The calculated stress was corrected for (1) the instantaneous change in cross-sectional area due to sample shortening, assuming that samples kept their cylindrical shape and constant volume and (2) apparatus stiffness. The stiffness of the deformation apparatus is determined in a separate experiment to be $82.5 \mathrm{kN} / \mathrm{mm}$.

Deformed olivine samples were recovered by cutting the assembly with a low speed saw. Thin sections of the deformed olivine and the hot-pressed samples were cut parallel to the deformation axis (long axis of the cylinder) after removal of $2 \mathrm{~mm}$ from the lower- and topmost parts, where stresses are expected to be heterogeneously distributed (Griggs et al., 1960). The heterogeneous stress distribution at the sample ends is caused by friction at the alumina spacersample interface, leading to a lower increase in sample radius during shortening compared to the center of the sample (i.e., barreling effect, see Moosbrugger, 2002). Thus the lower- and topmost parts were not mapped by EBSD. For some of the cold-pressed and hotpressed samples (CMT16-1, CMT16-5, CMT16-7), sections were cut perpendicular to the long axis from the ends of the sample cylinders, to preserve parts of the sample for later deformation.

\subsection{Scanning electron microscope based electron backscatter diffraction}

Grain size distributions, shapes and orientations, as well as the microstructure were analyzed by indexation of electron backscatter diffraction patterns in a scanning electron microscope (CamScan X500FE CrystalProbe) at Geosciences Montpellier. Sample sections and a small amount of the olivine powder were embedded in epoxy and polished, including a final chemo-mechanical polish using colloidal silica $(0.04 \mu \mathrm{m}$ particles, average polishing times of 1 hour). Exposed sample surfaces were carbon coated with a coating thickness of 10-20 $\mathrm{nm}$, leaving a non-coated window in the center of the sample for EBSD analyses. Working distance was 24 $-25.1 \mathrm{~mm}$, acceleration voltage was 17 to $17.5 \mathrm{~V}$ and the beam current was $10 \mathrm{nA}$ for EBSD map acquisition, down to $5 \mathrm{nA}$ for backscattered electron (BSE) imaging. In all cases, the acquired phases were olivine $\left((\mathrm{Mg}, \mathrm{Fe})_{2} \mathrm{SiO}_{4}\right)$, diopside $\left(\mathrm{CaMgSi}_{2} \mathrm{O}_{6}\right)$, enstatite $\left((\mathrm{Mg}, \mathrm{Fe}) \mathrm{SiO}_{3}\right)$ and chromite $\left((\mathrm{Fe}, \mathrm{Mg}) \mathrm{Cr}_{2} \mathrm{SiO}_{4}\right)$. EBSD data was obtained with the Oxford instruments HKL Aztec2 software and treated with the MTEX toolbox (Hielscher \& Schaeben 2008, Bachmann et al. 2010). Data treatment removed wild spikes and filled non-indexed pixels when 7 neighbors with identical orientations were present. Grain boundaries were identified where the misorientation to the next pixel is higher than $10^{\circ}$. Only grains with more than 5 pixels (corresponding to a minimum grain diameter of $0.6 \mu \mathrm{m}$ ) were considered for further calculations. The density of the orientation distribution function was calculated using an axially symmetric de la Vallee Poussin kernel, with half-width of $10^{\circ}$ (bandwidth of 28 in spherical harmonic coefficients). Crystal preferred orientations (CPO) and the texture J-index (Bunge, 1982) were calculated. The texture J-index is a measurement of the texture strength calculated as the integral of the square of the orientation distribution function. Contrary to some past studies, here the Jindex is calculated as area weighting to not overestimate the contribution of numerous small grains. Densities of pole figures of the CPO were normalized to a uniform distribution and contoured at intervals of $0.5 \times$ uniform. The BA-index was introduced by Mainprice et al. (2014) to characterize the symmetry of olivine pole figures [100] and [010].

A total of 121 EBSD maps from 16 samples were aquired. Out of 121 maps, 33 large scale maps $\left(>20000 \mu^{2}\right.$ ) free of charging and drifting artifacts with step sizes of $0.2 \mu \mathrm{m}$ (hot-pressed and deformed samples) or $1 \mu \mathrm{m}$ (olivine powder and cold-press) were used to calculate microstructure and texture characteristics as the arithmetic mean of all suitable maps of a given sample. Consequently, the number of map pixels and grains used for calculation is high (e.g., 2416 to 38675 grains per sample). For local and grain scale maps $\left(<2400 \mu \mathrm{m}^{2}\right)$, step sizes as low as 0.05 $\mu \mathrm{m}$ were sucessully applied for the first time on olivine agregates without electrostatic charging and drifting. The full set of EBSD parameters is given in supplementary Table $\mathrm{S} 1$ and a relevant selection is reported in Table 2. 


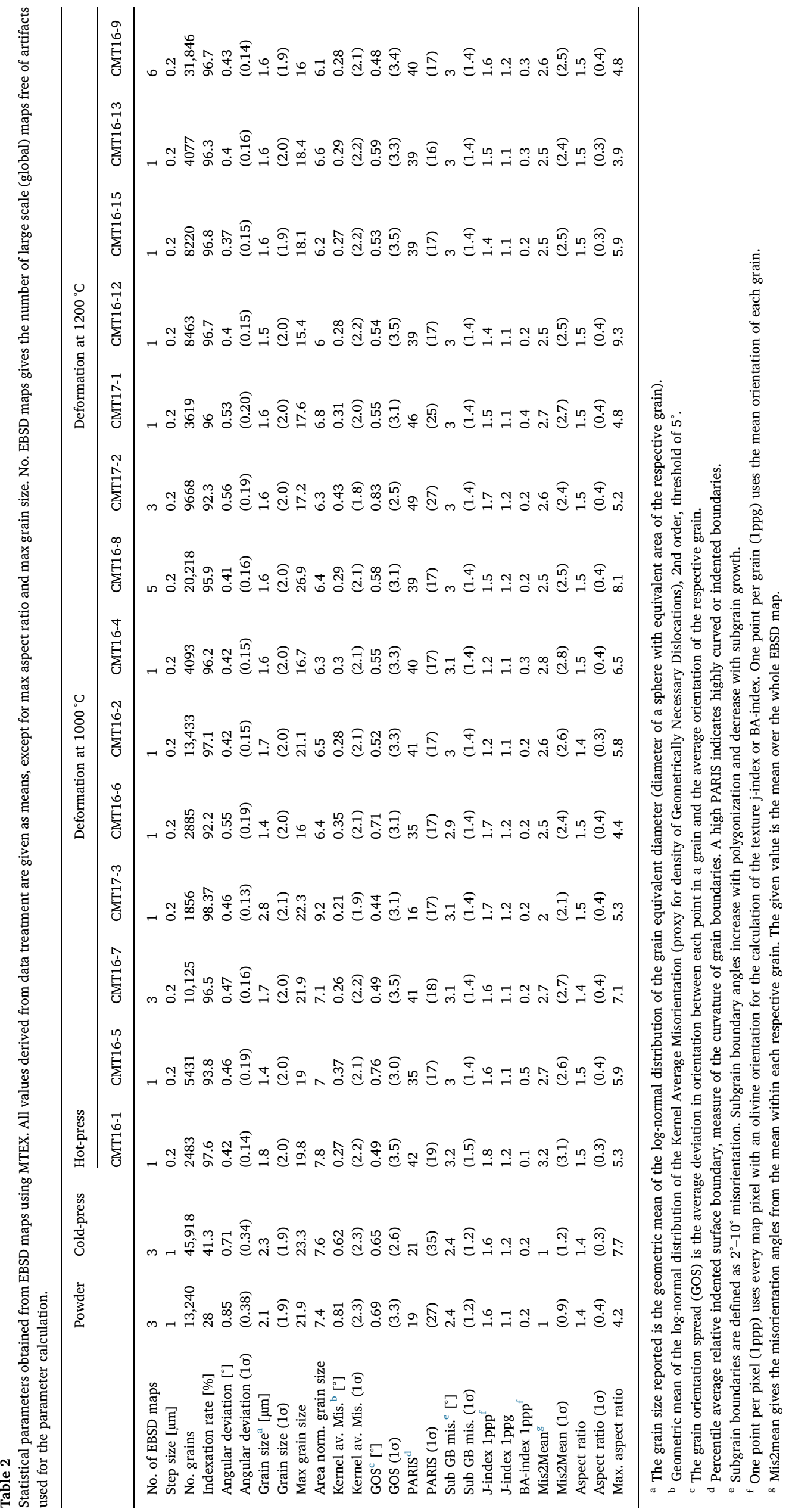




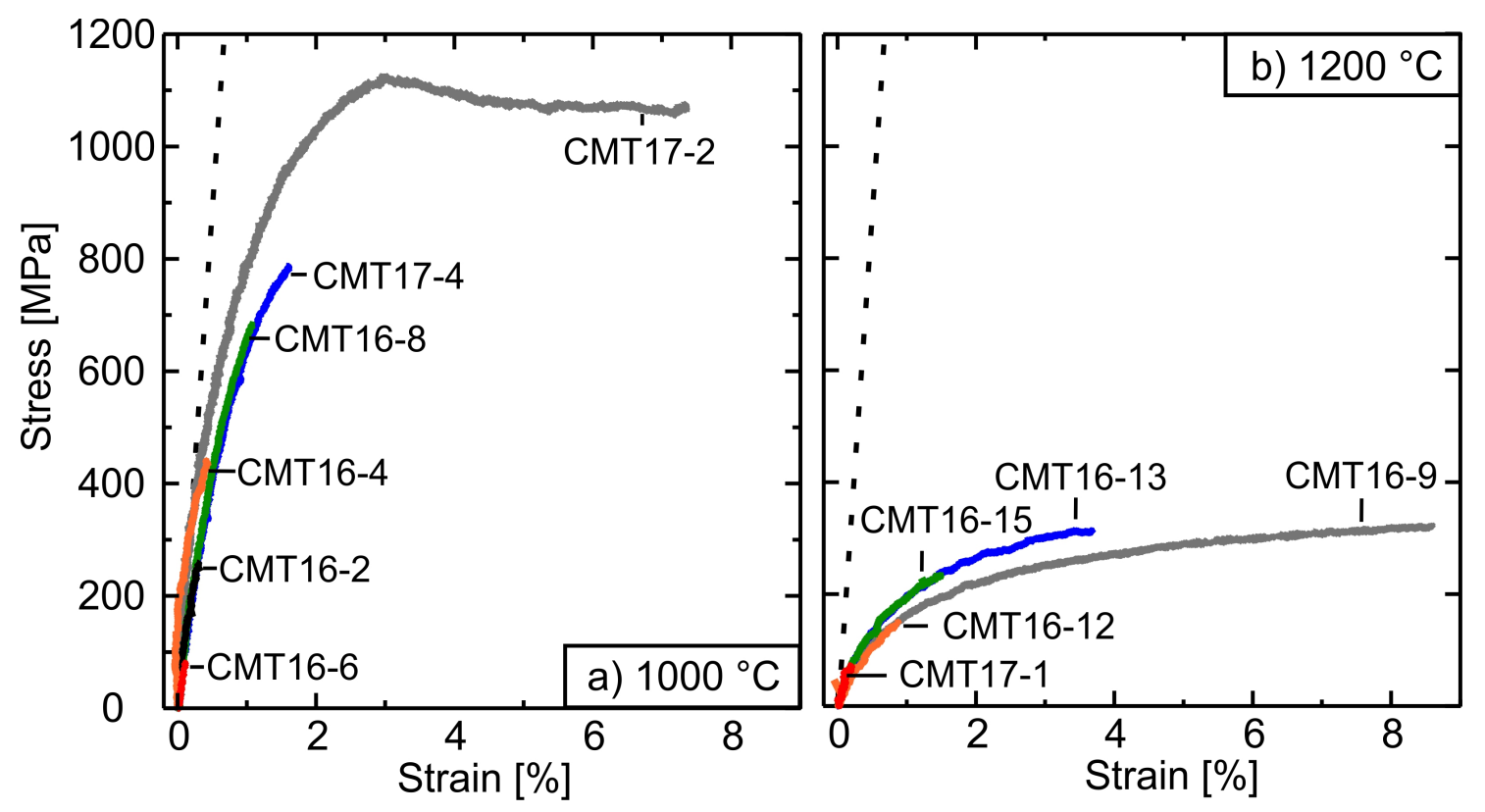

Figure 1 Differential stress versus strain curves for experiments at constant displacement rate, $300 \mathrm{MPa}$ of confining pressure, (a) $1000{ }^{\circ} \mathrm{C}$ and (b) $1200{ }^{\circ} \mathrm{C}$. Pure elastic deformation of polycrystalline San Carlos olivine is shown with dashed lines, based on a Young's modulus of (a) $152 \mathrm{GPa}$ and (b) $146 \mathrm{GPa}$ (Liu et al., 2005).

\subsection{Transmission electron microscopy (TEM)}

Transmission electron microscopy (TEM) was used to characterize the microstructures after the deformation experiments. Doubly polished thin sections $(30 \mu \mathrm{m}$ thick) of all deformed samples and hot-pressed sample CMT16-7 were prepared. The sample sections were cut parallel to the deformation axis. They were glued on a grid ( $\mathrm{Cu}$ or $\mathrm{Mo}$ ) and ion milled at $5 \mathrm{kV}$ under a low beam angle of $15^{\circ}$ until electron transparency was reached. The foils were subsequently covered with a thin layer of carbon. TEM observations were carried out at the University of Lille (France) using a Philips CM30 microscope operating at $300 \mathrm{kV}$ and a $\mathrm{FEI} \circledast$ Tecnai G2-20 twin microscope operating at $200 \mathrm{kV}$.

\section{Results}

\subsection{Mechanical results}

The results of the deformation experiments are reported in Table 1 and all stress-strain curves are shown in Figure 1. Optical microscopy of sample thin sections shows cracks that are sub-parallel to the long axis of the sample cylinder (the compression axis). There is no relative displacement along the cracks or shearing visible on the iron-jacket. The permanent finite strains range from 0.1 to $8.6 \%$ and the strain rates range from $1.8 \times 10^{-6} \mathrm{~s}^{-1}$ for low finite strain $(<0.5$
$\%$ of strain) to $1 \times 10^{-5} \mathrm{~s}^{-1}$ at high finite strain (> $4 \%$ of strain). At $1000{ }^{\circ} \mathrm{C}$, the stress-strain curve departs

systematically from linear (elastic) behavior, even for strains below $0.5 \%$. The stress reaches a maximum of $1127 \mathrm{MPa}$ at $3 \%$ of finite strain (sample CMT17-2), at which point it drops by $60 \mathrm{MPa}$ and becomes apparently independent of finite strain. At 1180-1200 ${ }^{\circ} \mathrm{C}$, stress increases at a lower rate, reaching a maximum of $322 \mathrm{MPa}$ at $8.6 \%$ of finite strain (CMT169). No perfect steady state is reached; stress continues to increase at a very slow rate of $4 \mathrm{MPa}$ per percent of strain. From the mechanical data, there is no evidence of stick-and-slip or brittle failure of the samples. At the same temperature and very similar displacement rates, the stress-strain curves differ slightly. As an example, samples CMT17-2 and CMT17-4, both deformed at $1000{ }^{\circ} \mathrm{C}$, reach 954 and $787 \mathrm{MPa}$ of stress respectively at $1.6 \%$ of strain. Samples CMT16-9 and CMT16-13, both deformed at $1180{ }^{\circ} \mathrm{C}$, reach 265 and $313 \mathrm{MPa}$ of stress respectively at $3.7 \%$ of finite strain.

The Young's modulus $E$ of San Carlos olivine was calculated assuming the isotropic relation

$$
E=2 G(1+v)
$$

where $G$ is the shear modulus and $v$ is Poisson's ratio. The shear modulus $G$ was calculated for the respective temperatures and pressures using an initial shear modulus $G_{0}$ of $77.4 \mathrm{GPa}$, a pressure dependence $G_{0}^{\prime}$ of 1.61 and a temperature dependence $\delta G_{d} \delta T$ of $-0.0130 \mathrm{GPa} / \mathrm{K}$ (Liu et al., 2005). By comparison with the deformation curves, neither at $1000{ }^{\circ} \mathrm{C}$, nor at $1200{ }^{\circ} \mathrm{C}$ do the curves exhibit a linear segment indicating pure elastic 


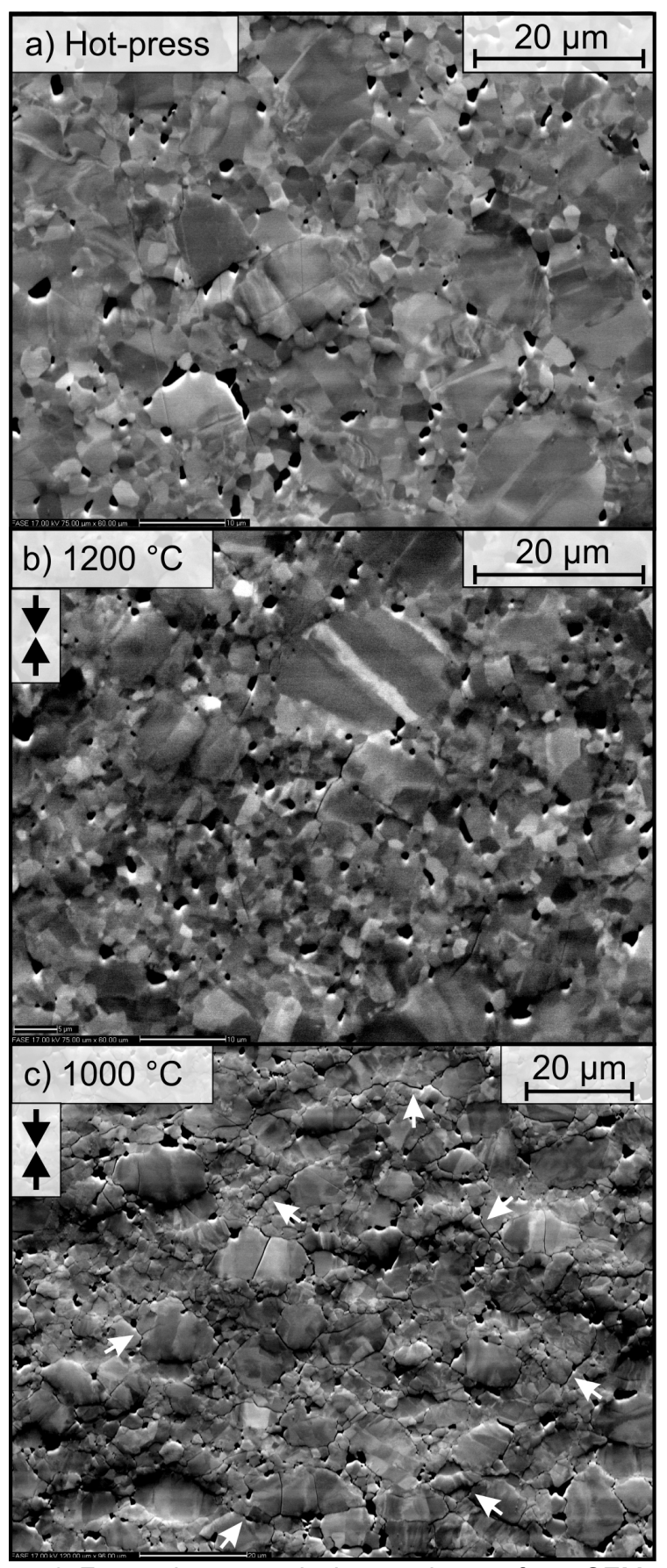

Figure 2 Forward scattered electron image from SEM. (a) prior to deformation (hot-press CMT16-7); (b) after deformation at $1200{ }^{\circ} \mathrm{C}$ and for $8.6 \%$ of finite strain (CMT169); (c) after deformation at $1000{ }^{\circ} \mathrm{C}$ and for $7.3 \%$ of finite strain (CMT17-2). Dark areas are plug outs from polishing and pores. White arrows show cracks developed by brittle deformation.

deformation. To determine if the deformation is mostly the result of anelasticity (stress and time dependence of elastic strain), we have subjected an already deformed sample (CMT17-4, $1000^{\circ} \mathrm{C}, 1.6 \%$ strain) to axial deformation. The pre-deformed sample reaches significantly higher stresses for the same values of finite strain, as displayed in Supplementary Figure S2. This suggests, that even at low values of finite strain, there is significant plastic deformation and hence hardening.

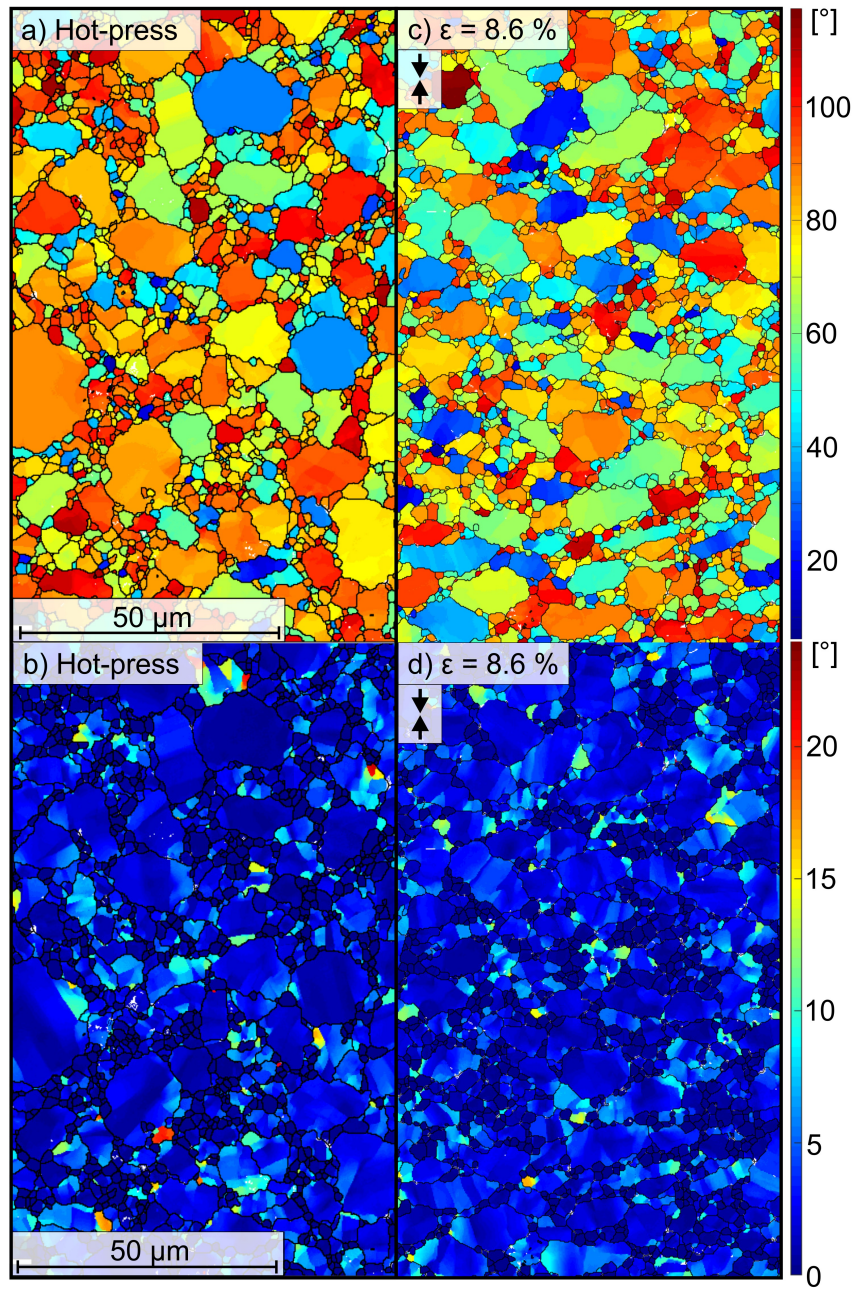

Figure 2 EBSD maps prior to deformation ( $a$ and $b$, hotpress CMT16-7) and post deformation (c and d, CMT16-9, $1200{ }^{\circ} \mathrm{C}$ ), showing the misorientation to a central reference point $(\mathrm{a}, \mathrm{c})$ and the misorientation to the mean orientation within each respective grain (b, d) of the same sample areas. Grain boundaries are defined as $10^{\circ}$ misorientation, and are drawn as black lines.

\subsection{Microstructure results}

Forward scattered electron images of the starting material and representative deformed samples are shown in Figure 2 and representative maps of the misorientation to a reference point and to the mean of each respective grain are shown in Figure 3. Data for samples not shown can be given upon request. Olivine comprises $>99.8 \%$ area of all samples, with diopside, enstatite and chromite as secondary phases $(<0.1$ $\%_{\text {area }}$ ). Indexation rates range from $93.3 \%$ to $98.7 \%$ in the hot-pressed or deformed samples and $27.9 \%$ to $41.3 \%$ in the cold-pressed and powder samples. Grains in all samples are tabular, shorter in the compression direction, with a mean aspect ratio of 1.4 - $1.5\left(\mathrm{~d}_{\max } / \mathrm{d}_{\min }\right)$ and a maximum aspect ratio of 3.0 (Table 1, Figure $4 a$ ). The long axis of the grain is preferentially oriented at $180^{\circ}$ to the compression axis (or vertical axis in case of the olivine powder) in all samples, as shown in Figure 5. Grain boundaries, and 
part of the sub-grain boundaries, are curved or
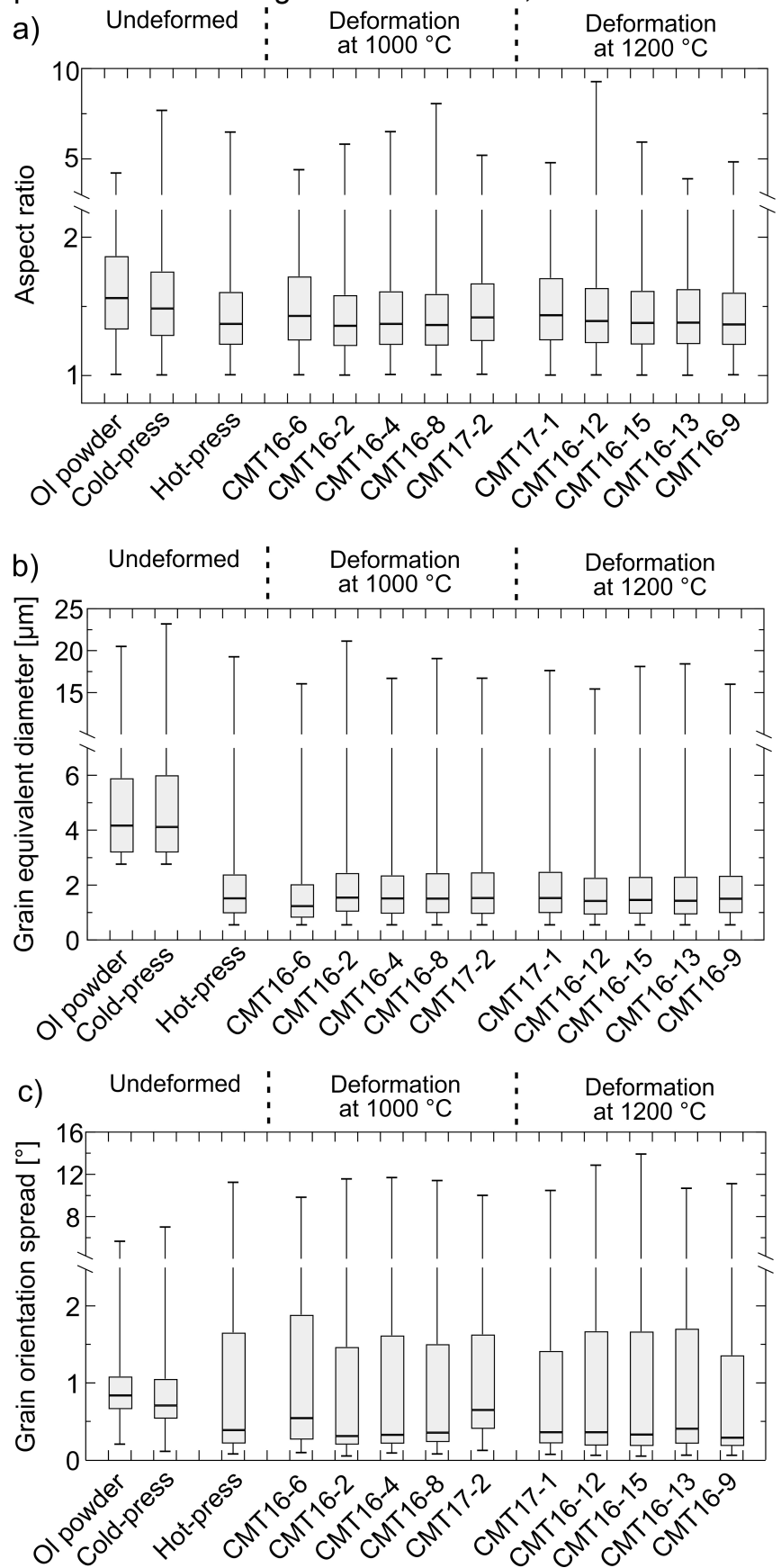

Figure 3 Distribution of the (a) equivalent grain diameter, (b) grain aspect ratio $\left(d_{\max } / d_{\min }\right)$ and $(c)$ grain orientation spread for each experiment. The whiskers represent the minimum and maximum values. The olivine powder and cold-press samples show apparent higher values due to higher EBSD step sized used for data acquisition ( $1 \mu \mathrm{m}$ instead of $0.2 \mu \mathrm{m})$.

serrated. Grain internal misorientation occurs in all stages from gradual misorientation to well developed polygonization. Triple junctions are dominant, but apparent 4-grain junctions can be seen in several EBSD maps as well. BSE images reveal occasional cracks inside the grains that are oriented at $60^{\circ}$ to each other. These rare cracks are already present in the olivine powder and there is no sign of displacement or sliding along them. Sample CMT17-2, deformed at $1000{ }^{\circ} \mathrm{C}$ to a finite strain of $7.3 \%$ exhibits a higher density of cracks crossing several grains or

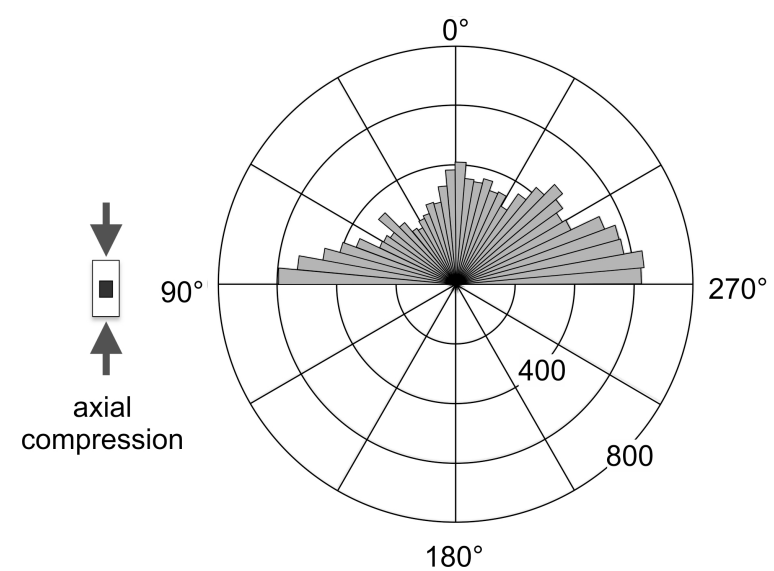

Figure 4 Representative rose diagram of the orientation of the longest axis of the olivine grains relative to the compression axis (sample CMT16-9). Olivine long axes are preferentially aligned perpendicular to the compression axis. The radius of the rose diagram gives counts, bins are $5^{\circ}$.

on grain boundaries, indicating that CMT17-2 deformed by micro-cracking after reaching a peak stress of 1073 MPa. See Supplementary Figure S3 for SEM images of sample CMT17-2 showing graininterior cracks and pairs of cracks at an angle of $\sim 45$ $\%$ to the compression axis. Porosity from plucking during sample polishing is higher in samples with shorter hot-press durations or lower hot-press temperatures (e.g. CMT16-5 and corresponding deformed sample CMT16-6). Excluding plug outs, porosity makes up less than $3 \%$ area as observed for similar experiments (Beeman \& Kohlstedt, 1993; Hirth \& Kohlstedt, 1995; Hansen et al., 2012).

Representative grain size distributions obtained using MTEX as the diameter of a circle with an area equivalent to the respective grain are shown in Figure 6. The grain size distribution is similar for all samples, there is no significant change as a function of finite strain or temperature as shown by Figure $4 \mathrm{~b}$. The mean equivalent diameter calculated from the lognormal distribution ranges from $1.4 \pm 2.0 \mu \mathrm{m}$ to $1.7 \pm$ $2.0 \mu \mathrm{m}$ (geometric mean, $1 \sigma$ ) for the deformed samples and their respective hot-presses. The high geometric standard deviation reflects the broad distribution of grain sizes. The microstructure of the hot-pressed and deformed samples are identical to the one of the powder and cold-press samples, taking into account measurement errors and higher EBSD step sizes in the powder and cold-press. It is likely inherited from the original powder and shape preferred orientation due to sedimentation effects while loading the capsule. The grain shape is likely related to perfect cleavage of olivine on (010) (Deer et al, 1997; Hawkes, 1946; Velinskiy \& Pinus, 1969; Kuroda \& Shimoda, 1967; Kuijper, 1979) during pulverization.

Accounting for sectioning bias (factor of 1.5 for nonspherical olivine grains; Underwood, 1970), this 
equals a true mean grain diameter of 2.1-2.6 $\mu \mathrm{m}$.
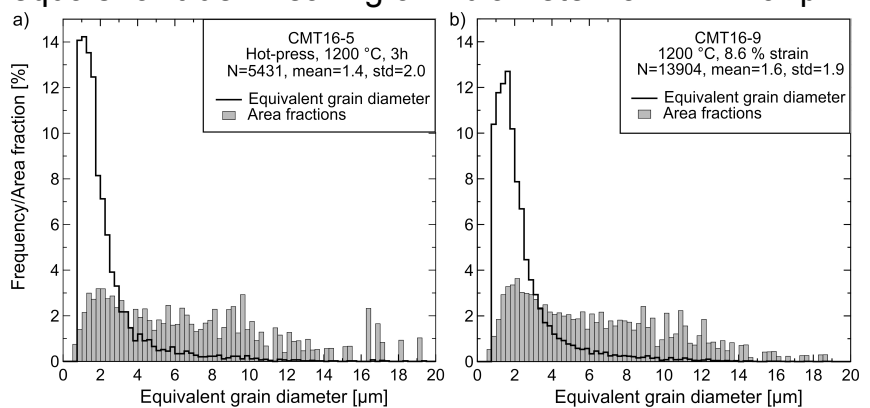

Figure 6 Representative grain size distribution of (a) a hotpressed sample (CMT16-5), and (b) a sample deformed at $1200{ }^{\circ} \mathrm{C}$ to $8.6 \%$ of strain. Grain sizes are calculated as the diameter of a circle with an equivalent area to the grain. $\mathrm{N}$ gives the number of grains used for the grain size calculation. The mean is calculated as the geometric mean.

Normalized by area, the distribution broadens with grains up to $27 \mu \mathrm{m}$ in equivalent diameter taking up a sizeable fraction of the sample area. Due to the calculation method (i.e., only considering grains consisting of more than 5 pixels), the smallest grains have a equivalent diameter of $0.6 \mu \mathrm{m}$. For the coldpress and powder samples, a higher EBSD step size of $1 \mu \mathrm{m}$ was used. Consequently, the average grain size appears to be higher, with $2.1 \pm 1.9 \mu \mathrm{m}$ for the olivine powder and $2.3 \pm 1.9 \mu \mathrm{m}$ for the cold-press (Table 1).

All samples, including the undeformed olivine powder, show an axial [010] pattern of the texture, as shown in Figure 7. Crystal [100] and [001] axes are aligned in a girdle perpendicular to the compression axis, and [010] axes are parallel to the compression axis. The J-index (area weighted) ranges from 1.2 to 1.8 , and is not changing significantly in between samples. Calculated for one mean orientation per grain, the J-index is slightly lower, ranging from 1.1 to 1.2 .

a) Powder: $20{ }^{\circ} \mathrm{C}, \varepsilon=0 \%$, J-index $=1.6$
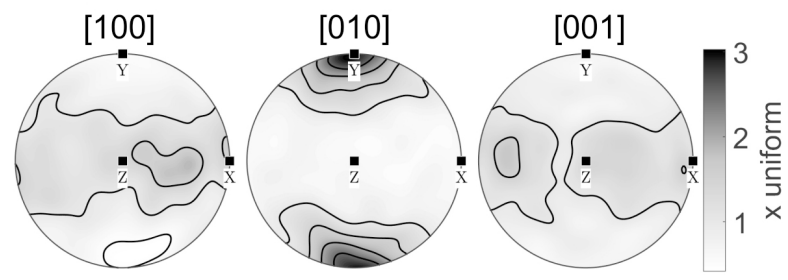

c) CMT $16-8: 1000{ }^{\circ} \mathrm{C}, \varepsilon=1.1 \%$, J-index $=1.6$
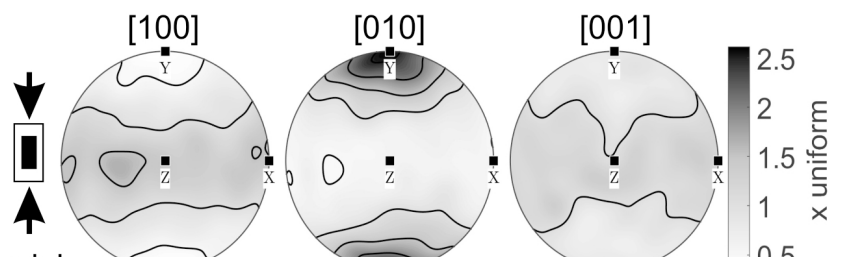

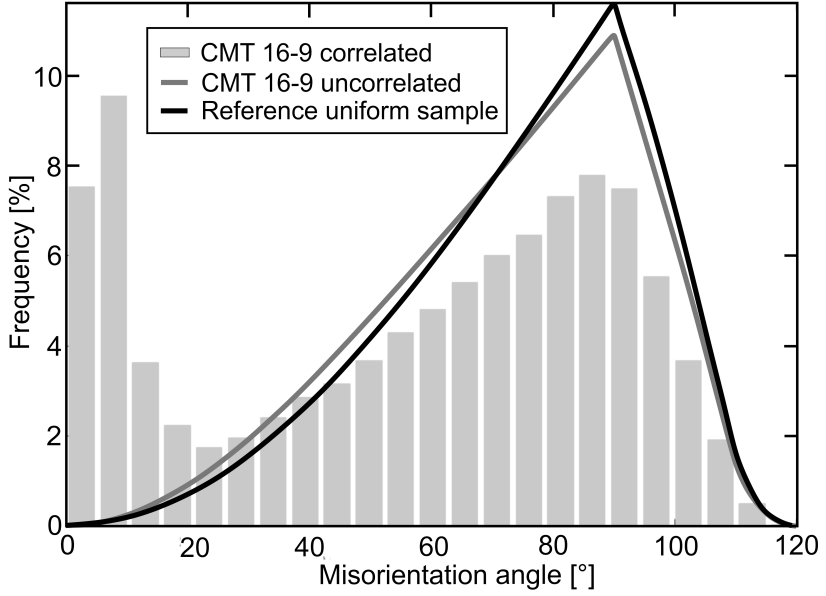

Figure 8 Representative histogram of the correlated, uncorrelated and uniform misorientation angles using a lower bound of $2^{\circ}$. Grey bars show boundaries in CMT 169. The black line is calculated for a uniform, randomly oriented sample. The grey line is calculated from uncorrelated measurement pixels (spaced apart) and can be compared to the uniform sample to estimate the texture influence, which is small here.

The frequency of grain boundaries as a function of their misorientation angle is displayed in Figure 8. The given histogram (CMT16-9) is representative of all samples. We show the correlated misorientation angles (i.e., from neighboring pixels). In MTEX, the uncorrelated misorientation angle distibution is calculated using the orientation distribution function (ODF) harmonic coefficients and only reflects the influence of the CPO and nothing else. The uniform misorientation angle distribution is calculated using the analytical method of Morawiec (2004). Note that a deviation of the uncorrelated angles from the uniform distribution therefore shows the influence of texture, while the distribution of the correlated angles depends on the occurence of deformation-related (sub)grain boundaries. The most commonly occuring low angle boundaries have

b) Hot-press: $1200{ }^{\circ} \mathrm{C}, \varepsilon=0 \%$, J-index $=1.6$

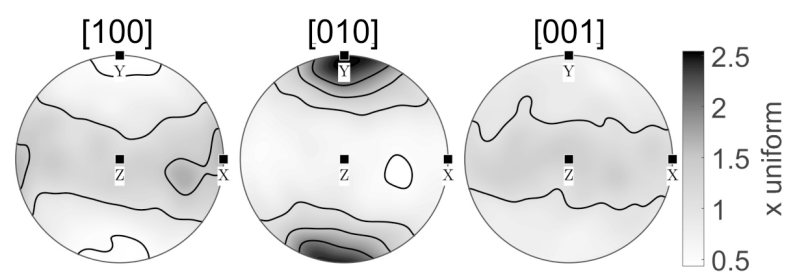

d) CMT16-9: $1200{ }^{\circ} \mathrm{C}, \varepsilon=8.6 \%$, J-index $=1.6$

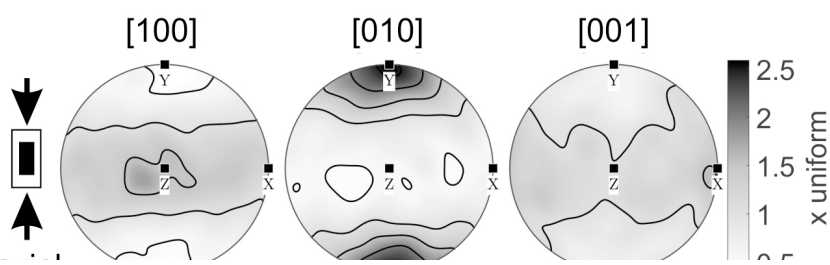

coFigure 5 Lower hemisphere pole figures of the crystal preferred orientation for (a) the olivine powder; (b) a representative hotpressed olivine sample; (c) the olivine sample deformed at $1000{ }^{\circ} \mathrm{C}(\mathrm{CMT16}-8)$ and (d) the olivine sample with the highest finite strain deformed at $1200^{\circ} \mathrm{C}(\mathrm{CMT} 16-9)$. The pole figures were calculated using one point per pixel. 
misorientations of up to $20^{\circ}$, with a strong maximum at $10^{\circ}$ (10\% frequency).

High angle boundaries increase in frequency towards a maximum at $90^{\circ}$ (8\% frequency), resulting in a negatively skewed distribution. The uncorrelated misorientation angles match the uniform distribution, with only a higher frequency of angles below $\sim 70^{\circ}$ than in the random distribution. The misorientation from the mean within each grain is log-normal distributed with angles up to $15^{\circ}$ as plotted in Figure 9 . The misorientation axis of these low-angle boundaries of up to $15^{\circ}$ can be plotted in crystallographic coordinates. The resulting inverse pole figure, representative for the hot-pressed and deformed samples, is displayed in Figure 10. Most misorientation axes are close to the crystallographic [001] direction with a strong maximum of $8 \times$ uniform. There is a weak secondary concentration around the [010] direction. The distribution of the misorientation axes does not change significantly between samples deformed at $1000^{\circ} \mathrm{C}$ and $1200^{\circ} \mathrm{C}$ or as a function of finite strain.

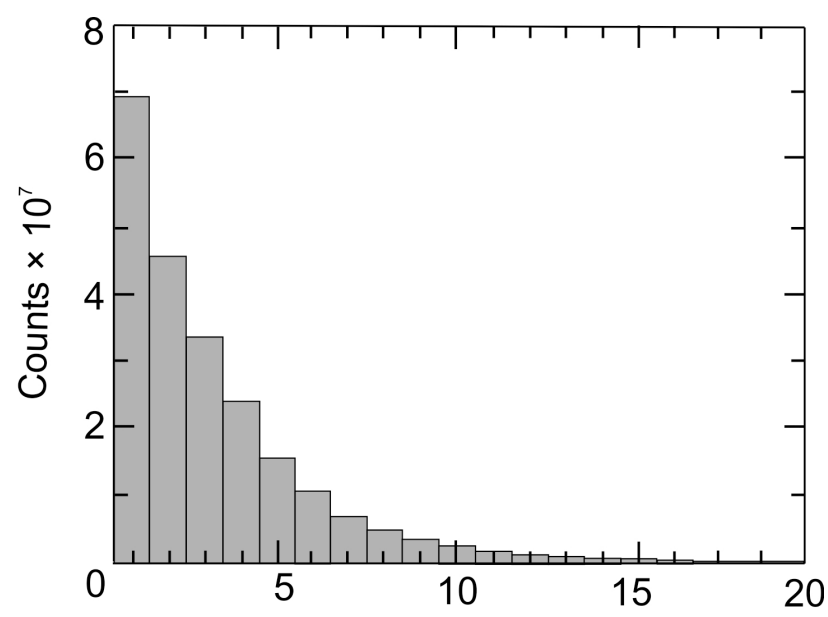

Figure 9 Histogram of the misorientation to the mean within each respective olivine grain (CMT16-9). This distribution is representative of all samples. The misorientation is lognormal distributed with angles up to $16^{\circ}$.

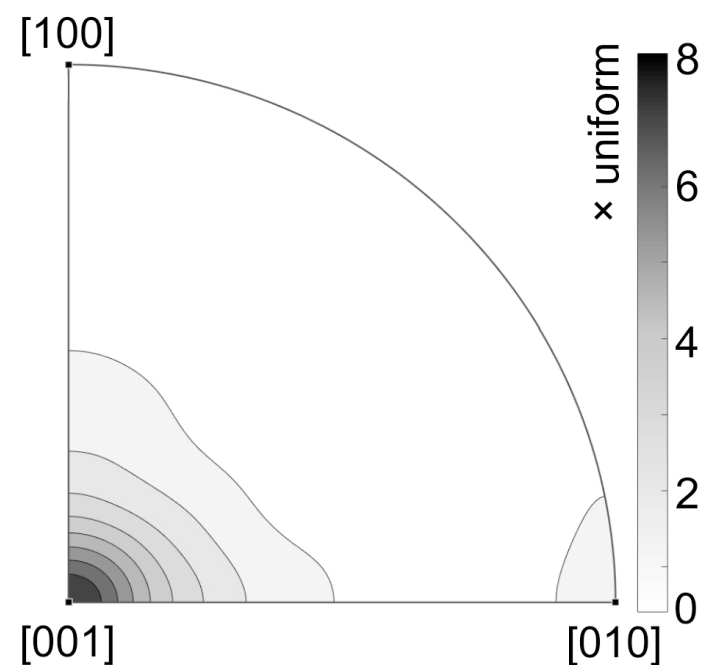

Figure 10 Representative inverse pole figure of the misorientation axes of olivine grain boundaries in crystal coordinates for misorientation angles between 2 and $15^{\circ}$.

\subsection{Transmission Electron Microscopy}

Typical weak-beam dark-field TEM images of the dislocation microstructures are given in Figure 11. All samples exhibit unambiguous dislocation activity. The most striking feature is the rather strong heterogeneity of the microstructures in all samples which does not allow a simple trend to be found among them. Even at the lowest temperatures considered (1000-1030 ${ }^{\circ} \mathrm{C}$ ) both [100] and [001] dislocations activity is found (Fig. $11 \mathrm{a}, \mathrm{b})$ from quite small finite strains $(1.41 \%$ in case of CMT16-2). Dislocation line shapes suggest high lattice friction, but dislocations already organize into subgrain boundaries. Even at the highest temperature considered $\left(1200{ }^{\circ} \mathrm{C}\right)$ deformation is very heterogenous with some grains almost or completely pristine (Fig. 11c) and some other exhibiting dislocation densities of the order of $10^{14} \mathrm{~m}^{-2}$. Several observations of grain boundaries acting as sources for dislocations have been found. The samples contain residual pores which do not appear to be sites where plasticity concentrates. In grains displaying evidence of [100] and [001] slip activity, there is no evidence of interaction between the dislocations from the different slip systems.

\section{Discussion}

\subsection{Mechanical data}

The maximum differential stresses of our experiments at $1000{ }^{\circ} \mathrm{C}$ exceed the confining pressure by a factor of up to 3.5. The confining pressure $(P)$ acts by opposing volume expansion (e.g. Edmond \& Paterson, 1972) and against crack nucleation and propagation. The Goetze criterion, first proposed by Briegel and Goetze (1978), defines a critical stress needed to initiate crack nucleation as $\sigma_{1}-\sigma_{3}=P$ (see also Kirby, 1980; Evans \& Kohlstedt 1995). With the exception of CMT17-2, there is no evidence for displacement along cracks in SEM images of our samples. On the short time scales of our experiments, the Goetze criterion does not hold true. For deformation experiments at $1000{ }^{\circ} \mathrm{C}$, the present stress-strain curves are consistent when compared to previous mechanical results for polycrystalline olivine $\left(900{ }^{\circ} \mathrm{C}, 300 \mathrm{MPa}, 1 \times 10^{-5} \mathrm{~s}^{-1}\right.$ $3 \times 10^{-5} \mathrm{~s}^{-1}$, axial compression, with correction for the apparatus stiffness) from Demouchy et al. (2014). The 

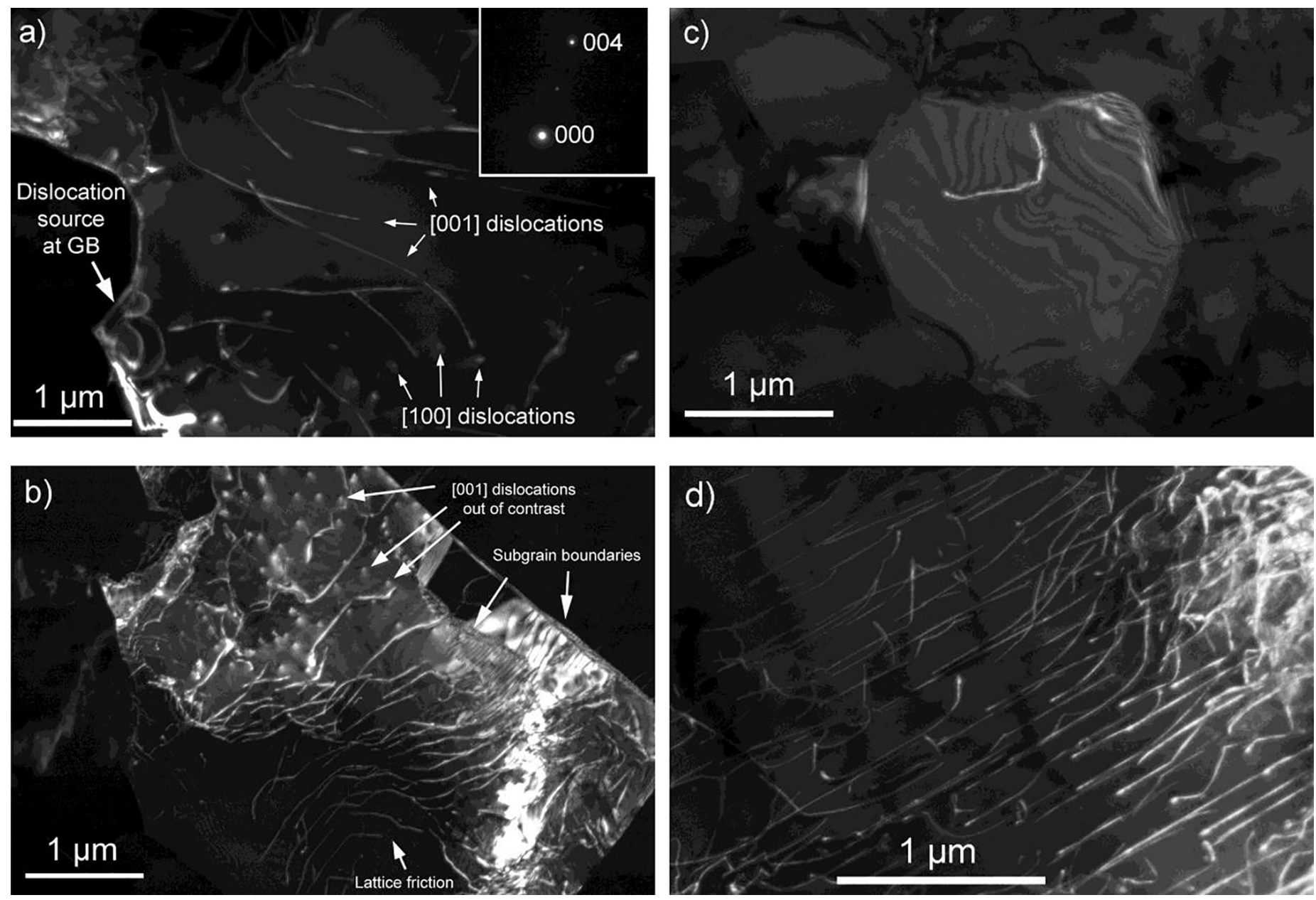

Figure 11 TEM weak-beam dark-field images of typical microstructures found in all samples. (a) Image from sample CMT16-2 showing a dislocation source at a grain boundary (diffraction vector g: 004). [001] dislocations are in contrast unless 100 dislocations for which only a residual contrast at the surface (white dots) can be seen. Both dislocation types are present. (b) Image from sample CMT16-8 displaying both [100] and [001] dislocations activity with the formation of subgrain boundaries (diffraction vector g: 004). [001] dislocations exhibit lattice friction. (c) Image from sample CMT16-9 showing a grain with almost no dislocation activity. (d) Image from sample CMT16-9 of a grain containing a dislocation density of $\approx 7 \times 10^{13} \mathrm{~m}^{-2}$.

sample CMT17-2 of this study reaches brittle failure at a higher stress of $1127 \mathrm{MPa}$, while sample PoEM22 of Demouchy et al. (2014) fails at $930 \mathrm{MPa}$ at $900{ }^{\circ} \mathrm{C}$. Note that both CMT17-2 of this study and PoEM22 of Demouchy et al. (2014) did not reach steady state before brittle failure and thus give only a lower bound of strength. For a given strain, samples in this study reach a lower stress, consistent with deformation at higher temperatures. The maximum stresses from our experiments at $1000{ }^{\circ} \mathrm{C}$ and existing low temperature (exponentional) flow laws are shown in Figure 12c. The maximum stress for $1.1 \%$ of finite strain at 1000 ${ }^{\circ} \mathrm{C}$ (CMT16-8, no steady state or brittle failure) surpasses recent calculations based on 2.5-D dislocation dynamics models for single crystals of olivine oriented for easy slip (Boioli et al. 2015; their Figure 3 ). In this study, they model a single glide direction, [100](001), in a olivine single crystal, therefore giving only a lower bound of the strength.
The experiment CMT17-2 reached brittle failure around $3 \%$ of finite strain, but the maximum stress before brittle failure of $1127 \mathrm{MPa}$ can be used. The stress surpasses steady state estimations from the single crystal flow laws from Evans \& Götze (1979) and Demouchy et al. (2013), but is in good agreement with the flow law based only on [001](100) glide from deformation experiments in shear from Tielke et al. (2016), as seen in Figure 12. The higher strength of our samples can at least partly be attributed to the lack of sufficient independent slip systems in polycrystalline olivine samples (the so called olivine paradox) and the difference between single crystal and polycrystal rheology (e.g., Evans and Goetze, 1979, their Fig 14).

The deformation curves of samples CMT16-13 and CMT16-9 obtained at $1200{ }^{\circ} \mathrm{C}$ (Figure 12b) show a quasi-steady-state mechanical behavior. Their respective maximum stresses fit well with the 
a) $1200{ }^{\circ} \mathrm{C}$

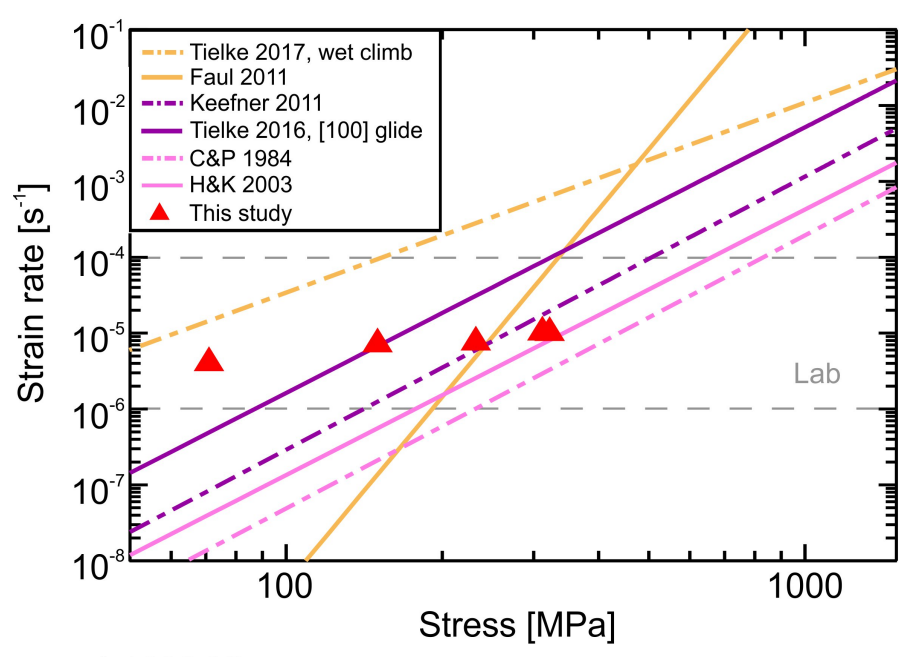

c) $1000^{\circ} \mathrm{C}$

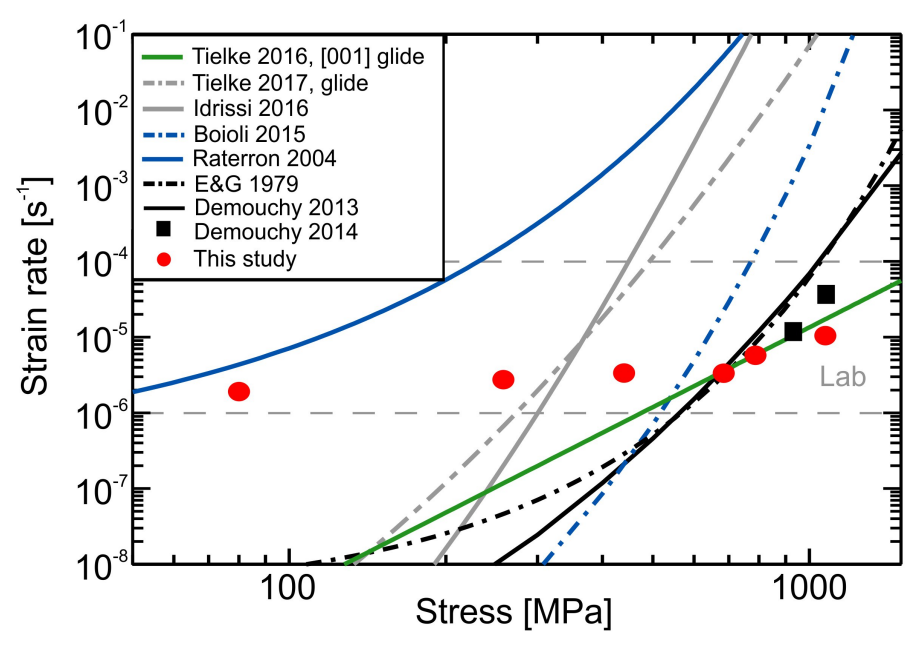

b) Strain rate $10^{-5} \mathrm{~s}^{-1} \quad$ Temperature $[\mathrm{K}]$

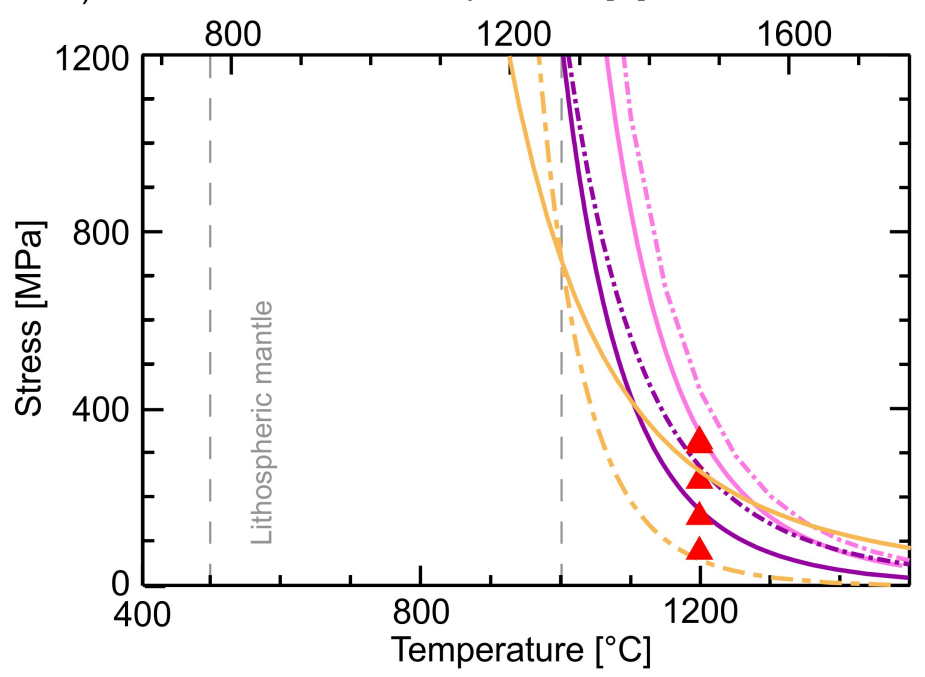

d) Strain rate $10^{-5} \mathrm{~s}^{-1} \quad$ Temperature $[\mathrm{K}]$

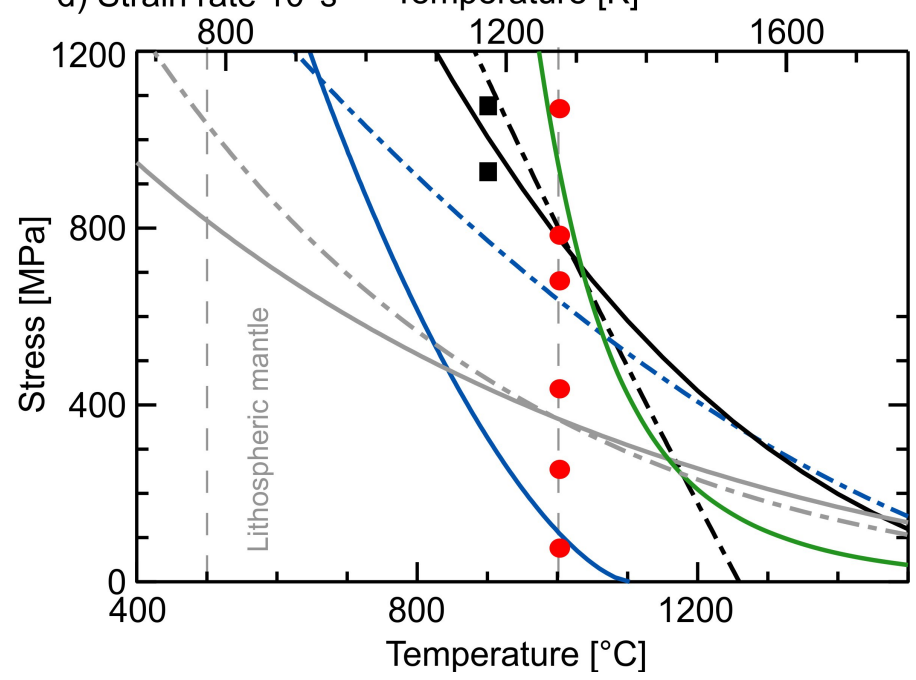

Figure 12 (a) Maximum stresses (red triangles) achieved for deformation at $1200{ }^{\circ} \mathrm{C}$ as a function of strain rate, compared to flow laws of previous studies. (b) Temperature-stress plot for deformation at $1200{ }^{\circ} \mathrm{C}$. (c) Maximum stresses (red squares) achieved for deformation at $1000{ }^{\circ} \mathrm{C}$ as a function of strain rate, black squares are maximum stresses from Demouchy et al. (2014). (d) Temperature-stress plot for deformation at $1000^{\circ} \mathrm{C}$. Flow laws are from Evans \& Goetze (1979), Chopra \& Paterson (1984), Hirth \& Kohlstedt (2003), Raterron et al. (2004), Faul et al. (2011), Keefner et al. (2011), Demouchy et al. (2013), Boioli et al. (2015), Idrissi et al. (2016), Tielke et al. (2016, shear on (100)[001] for $100{ }^{\circ} \mathrm{C}$ and (001)[100] for $1200{ }^{\circ} \mathrm{C}$ ) and Tielke et al. (2017, dry/wet glide for $1000{ }^{\circ} \mathrm{C}$ and wet climb for $1200{ }^{\circ} \mathrm{C}, 11-16 \mathrm{ppm} \mathrm{H} \mathrm{H}_{2} \mathrm{O}$ wt. or $190-260 \mathrm{ppm} \mathrm{H} / 10^{6} \mathrm{Si}$ ). The sample with the highest stress at $1000{ }^{\circ} \mathrm{C}$ (CMT17-2, $7.3 \%$ strain) did not reach steady state and gives a lower bound of strength.

dislocation creep flow law for Âheim dunite from Keefner et al. (2011, grain size of $0.9 \mathrm{~mm}$ ). The dislocation creep power law of Hirth \& Kohlstedt (2003, using data from Mei and Kohlstedt, 2000b for dry conditions) and the dislocation creep flow law for dry dunites from Chopra and Paterson (1984) surpass the stresses reached in our samples deformed at high temperature by $100 \mathrm{MPa}$ and $200 \mathrm{MPa}$ respectively.

\subsection{Deformation mechanisms \& microstructure}

While deformation is obviously plastic, one sample (CMT17-2) exhibits a higher density of cracks. Cracks generally exist in a subset of the grains in all samples, including the olivine powder, where they are more common and broader. They are therefore likely to be related to the powder preparation method of the olivine starting material (i.e., fluid energy pulverization). The pulverisation might also explain the aspect ratio of 1.4-1.5 seen in all samples, since (010) planes are distinct cleavage planes in iron-rich olivine (Deer et al, 1997; Hawkes, 1946; Velinskiy \& Pinus, 1969; Kuroda \& Shimoda, 1967; Kuijper, 1979). During hot-pressing these cracks mostly healed. Sample CMT17-2 exhibits a higher density of cracks, which are paired with their acute angle $\left(\sim 60^{\circ}\right)$ orientated nearly parallel to the compression axis; opening grain boundaries, as well as crossing several grains. We conclude that the sample CMT17-2 deformed in the brittle field by micro fracturing for a strain $>3 \%$ (at $1127 \mathrm{MPa}$, where the cuve flattens abruptly), while the other samples underwent no brittle failure. Rigid body grain rotation cannot be observed, since the 
orientation of the long axis of the grains stays constant.

The main deformation mechanism can be identified from comparison of the mechanical data to published flow laws and the alignment of low-angle boundaries. The maximal stresses of our experiments match existing dislocation creep flow laws for temperatures $>1100{ }^{\circ} \mathrm{C}$. Combined with the constant grain size, aspect ratio and TEM images, this suggests that dislocation creep was the dominant deformation mechanism, with a limited contribution of diffusion creep. The alignment of low-angle boundary misorientation axes parallel to the crystallographic [001] axis, shown in Figure 10, is common for tilt walls composed of [100]\{0kl\} dislocations, while the weak concentration parallel to the [010] axis is common for tilt walls built from [001](hk0) dislocations (Nicolas et al. 1973; Wenk et al. 1991; Tommasi et al. 2008; Farla et al. 2011; Demouchy et al. 2013, 2014). However, the grain boundary misorientation axes obtained from EBSD maps only represent preserved geometrically necessary dislocations (GND's, i.e., dislocations contributing to the lattice curvature). Therefore, the slip systems active during deformation might differ slightly (Raleigh, 1965, 1967, 1968; Carter \& Lallemant, 1970; Durham, 1975; Poirier, 1975; Tommasi et al., 2008; Soustelle et al., 2010; Demouchy et al. 2014). The distribution of grain boundary misorientation angles (Figure 8) showing a peak at $90^{\circ}$ is typical for a uniform distribution for orthorhombic crystal symmetry (Morawiec, 2004). The secondary peak at $10^{\circ}$ matches well with observations from Marquardt et al. (2015), who investigated the grain boundary character distribution of undeformed synthetic and natural polycrystalline olivine.

The microstructures of the hot-pressed and deformed samples are identical. In particular, the distribution of deformation axes does not change in between hot-presses and experiments performed at $1000{ }^{\circ} \mathrm{C}$ and $1200{ }^{\circ} \mathrm{C}$ and as said above (4.2), it is due to perfect cleavage of olivine on (010) during powder preparation. The $[100](001)$ slip system therefore seems not to be solely or preferentially activated in samples deformed at $1000{ }^{\circ} \mathrm{C}$, compared to deformation at $1200{ }^{\circ} \mathrm{C}$, which is consistent with experiments of Raleigh (1968) and Phakey et al. (1972). Likewise, the crystal preferred orientation (Figure 7) does not change or increase in intensity, which is expected for low values of finite strains (Nicolas et al., 1973, Zhang \& Karato, 1995; Skemer et al., 2012), and is confirmed here, even if high differential stresses are reached. We tried to hot-press an olivine aggregate for $20 \mathrm{~h}$ at $1270{ }^{\circ} \mathrm{C}$ (CMT17-3) and it produced only a limited grain growth to $2.8 \mu \mathrm{m}$ and no significant reduction of dislocation density (as evidenced by the grain orientation spread and kernel average misorientation) or a change in texture (see $\mathrm{J}$ - and BA-index in Table 2). To significantly alter the starting microstructure, much longer hot-press durations (> $100 \mathrm{~h}$ ), a higher hot-press temperature (> $1300{ }^{\circ} \mathrm{C}$ ) or an addition of water (drastic change of thermodynamic conditions) would be needed and these grain growth conditions are beyond the scope of this study.

\subsection{Strain hardening during transient creep}

We have two opposing observations, which question the current understanding of strain hardening in olivine. The stress during deformation rises nonlinearly as a function of finite strain before reaching steady state or brittle failure. This hardening is dependent on the deformation temperature and must therefore be based on a thermally activated process. Based on observations on metals, hardening is explained by competing effect of reduction of the grain size, and an increasing dislocation density in the neoformed sub-grains acting as obstacles and yielding an increasing sub-grain boundary misorientation (Estrin et al., 1998; Nes, 1997). Yet, the microstructure of our samples does not change with increasing stress or finite strain. Since none of these mechanisms seem to hold true during transient creep of our samples, the question of the mechanism of strain hardening in our sample remains. Thus, we discuss here several possibilities:

(i) Dislocation interactions: In metals, plastic strain hardening is commonly interpreted as the consequence of gliding dislocations interacting with the so-called forest dislocations (i.e. dislocations lying in different planes). This effect is reinforced by the possibility in most cubic metals that dislocation interaction can lead to stable junctions. In olivine, the two Burgers vectors [100] and [001] are perpendicular, which allows only rare and weak junctions (Mussi et al. 2017). Indeed, Fig. 11a,b shows no strong interactions between [100] and [001] glide. Other hardening mechanisms resulting from dislocation dynamics are collinear interaction and double cross slip. Our observations although preliminary, do not show more of these features in the low temperature samples.

(ii) Dislocation Mobility: In this temperature range, olivine is expected to involve significant lattice friction and this is supported by observation of the shapes of dislocation lines. However, here again, qualitative indication of lattice friction can be found in all samples (e.g. Fig11b, d). It is to be remembered that in the thermally activated regime, temperature enters an exponential and hence that a difference of $200{ }^{\circ} \mathrm{C}$ can lead to significant enhancement of dislocation mobility which could not be detected from 
post-mortem observations. This contribution can therefore not be excluded.

(iii) Grain boundaries acting as obstacles: In low-temperature plasticity, grain boundaries play mostly the role of obstacles leading to the well-known Hall-Petch effect (Hansen, 2004; Louchet et al., 2006). With grain sizes of around $2 \mu \mathrm{m}$, the ratio of boundary area to grain volume is high. Therefore, the interaction of dislocations with grain boundaries might play a role by preventing easy transfer of plastic activity from grain to grain. The formation of pile-ups might cause sufficient back stresses to be a source of hardening. However, we did not observe more evidence for pileups in samples deformed at the lowest temperatures than at the highest temperature.

(iv) Grain boundaries acting as dislocation sources. For plastic deformation to proceed, dislocation multiplication mechanisms are necessary. Inside grains, multiplication is usually attributed to the operation of Frank-Read sources (Frank \& Read, 1950), although they are rarely clearly observed. Our study follows this trend since we did not observe such sources. Instead, we observed several occurrences of dislocations being emitted from grain boundaries. We have no information about the ability of grain boundaries in olivine to act as dislocation sources and how temperature influences this mechanism. We note that the sources observed only produce a few loops. The hypothesis that dislocation nucleation represents a limiting factor in this temperature range cannot be further established or discarded.

(v) Grain boundaries acting as agent of deformation. Dislocation activity might not be the only deformation mechanism acting and in the recent years, a growing body of evidence has lead to establish grain boundary processes as a contribution to creep of olivine aggregates. This is most often attributed to the so-called grain boundary sliding mechanism (i.e., relative tangential motion of adjacent grains parallel to their common boundary; e.g. Hirth \& Kohlstedt, 1995; Langdon, 2006 ; Hansen et al. 2011) although other mechanisms described as shear-induced boundary migration, possibly involving disclinations, have also been proposed (Cordier et al., 2014). Grain boundary sliding was proposed to be active under high stresses and moderate to low homologous temperatures in olivine $\left(T_{m}\right.$ of Fo90 $=1765{ }^{\circ} \mathrm{C}$, Bowen \& Schairer, 1935; Wang, 2016) but also at temperatures very close to melting temperature and for a restricted type of tilt boundaries (e.g., in gold, Cahn et al., 2006). Without suitable markers (i.e., grid or dot-array of deposited metal or electron engraving, Quintanilla-Terminel et al., 2017), we cannot determine if these mechanisms were more active at $1200^{\circ} \mathrm{C}$ than at lower temperatures.

\subsection{Implications for the uppermost mantle}

Temperature conditions in our experiments (i.e., $1000{ }^{\circ} \mathrm{C}$ ) correspond to the uppermost lithospheric mantle, just below the MohorovičićDiscontinuity. This layer acts as an imperfect mechanical boundary between the convecting mantle and the lithospheric plates. The maximum stresses obtained by our samples at $1000{ }^{\circ} \mathrm{C}$ surpass predictions from existing flow laws for this temperature domain (exponential law), but are indeed significantly lower than prediction deduced from high temperature flow laws (power law), without the intervention of additional weakening mechanism such as water weakening (e.g., Mackwell et al., 1985; Demouchy et al., 2012) or partial melting (e.g., Kohlstedt \& Zimmerman, 1996). In consequence, the strength of olivine-rich rocks deformed at a temperature of 1000 ${ }^{\circ} \mathrm{C}$ and below, are in the order of 0.5 to $1 \mathrm{GPa}$ when extrapolated at the strain rate of the mantle (e.g. $10^{-14}$ $\mathrm{s}^{-1}$ ) which matches the requirement of a not so soft lithospheric mantle, ables to upkeep large orogens for millions of years (e.g., Mouthereau et al., 2013).

\section{Conclusions}

- Deformation at $1000{ }^{\circ} \mathrm{C}$ surpasses predictions from most previous low-temperature flow laws, but is in good agreement with Tielke et al. (2016, shear on [001](100)).

- Deformation at $1200{ }^{\circ} \mathrm{C}$ is in good agreement with Keefner et al. (2011), Tielke et al. (2016, shear on [100](001)) and Hirth and Kohlstedt (2003).

- The non-linear dependence of stress on finite strain (hardening) during early stage deformation is not correlated to a change in statistical microstructure measured by several parameters or texture strength and symmetry using EBSD maps.

- The samples with constant statistical microstructure however have a strength that is sensitive to finite strain, temperature and strain rate in a similar way to previously reported flow laws.

- The achieved stresses, constant grain sizes and absence of grain shape change fit well to dislocation creep as the main deformation mechanism. Grain boundary mechanisms would suggest a lower strength than observed.

- Glide on [100](0kl) is dominant, as evidenced by the alignment of low-angle boundaries parallel to the crystallographic [001] direction. 
- Even at early steady state (at $1200{ }^{\circ} \mathrm{C}$ ) and stresses of up to $1073 \mathrm{MPa}$, a sizeable subset of grains remains free of misorientation, which could be related to the small grain size.

- We further confirm that flow laws obtained at temperatures $>1200{ }^{\circ} \mathrm{C}$ cannot predict the strength of olivine deformed at $1000{ }^{\circ} \mathrm{C}$. The observed microstructures cannot explain the change in viscosity.

\section{Acknowledgements}

This project received funding from the European Union's Horizon 2020 research and innovation program under the Marie Sklodowska-Curie grant agreement No. 642029. We thank C. Nevado and D. Delmas for providing high-quality thin sections for SEM and TEM. N. Marino and J. Oustry are sincerely thanked for their help in the high-pressure lab and in the mechanical workshop. The TEM and EBSD-SEM national facilities in Lille and Montpellier are supported by the Institut National de Sciences de I'Univers (INSU) du Centre National de la Recherche Scientifique (CNRS, France), the Conseil Régional Occitanie/Pyrénées-Méditerranée (France), and by the Conseil Régional du Hauts-de-France, (France).

\section{References}

Bachmann, F., Hielscher, R., Schaeben, H., 2010. Texture analysis with MTEX - Free and open source software toolbox. Solid State Phenom. 160, 63-68.

http://dx.doi.org/10.4028/www.scientific.net/SSP .160.63.

Bai, Q., Mackwell, S.J. \& Kohlstedt, D.L., 1991. Hightemperature creep of olivine single crystals - 1 . Mechanical results for buffered samples. J. Geophys. Res. 96(B2), 2441-63.

Bai, Q., Kohlstedt, D.L., 1992. High-temperature creep of olivine single crystals, 2 . dislocation structures. Tectonophysics 206, 1-29. http://dx.doi.org/10.1016/0040-1951(92)90365D.

Beausir, B., Fressengeas, C., 2013. Disclination densities from EBSD orientation mapping. Int. J. Solids Struct. 50, 137-146. http://dx.doi.org/10.1016/j.jjsolstr.2012.09.016.

Beeman, M.L., Kohlstedt, D.L., 1993. Deformation of fine-grained aggregates of olivine plus melt at high temperatures and pressures. J. Geophys. Res. 98, 6443-6452. http://dx.doi.org/10.1029/92JB02697.

Boioli, F., Carrez, P., Cordier, P., Devincre, B., Marquille, M., 2015. Modeling the creep properties of olivine by 2.5-dimensional dislocation dynamics simulations. Phys. Rev. B 92, 1-12. http://dx.doi.org/10.1103/PhysRevB.92.014115.

Bowen, N.L., Shairer, J.F., 1935. The System MgOFeO-SiO 2 . Am. J. Sci. 29, 151-217.
Briegel, U., Goetze, C., 1978. Estimates of differential stress recorded in the dislocation structure of Lochseiten Limestone (Switzerland).

Tectonophysics 48(1-2), 61-76. http://dx.doi.org/10.1016/0040-1951(78)900860.

Buening, D.K., Buseck, P.R., 1973. Fe-Mg lattice diffusion in olivine. J. Geophys. Res. 78, 68526862. http://dx.doi.org/10.1029/JB078i029p06852.

Bunge, H.-J., 1982. Texture Analysis in Materials Science. Butterworths, London, p. 593. http://dx.doi.org/10.1016/B978-0-408-106429.50019-2.

Cahn, J.W., Mishin, Y., Suzuki, A., 2006. Coupling grain boundary motion to shear deformation. Acta Mater. 54, 4953-4975. http://dx.doi.org/10.1016/j.actamat.2006.08.004.

Carter, N.L. \& Avé Lallemant, H.G., 1970. High temperature deformation of dunite and peridotite. Geol. Soc. Am. Bull. 81, 2181-202.

Chakraborty, S., 2010. Diffusion coefficients in olivine, wadsleyite and ringwoodite. Rev. Mineral. Geochemistry 72, 603-639. http://dx.doi.org/10.2138/rmg.2010.72.13.

Chen, S., Hiraga, T. \& Kohlstedt, D.L., 2006. Water weakening of clinopyroxene in the dislocation creep regime. J. Geophys. Res. 111(B8), 2156202.

Chopra, P.N., Paterson, M.S., 1981. The experimental deformation of dunite. Tectonophysics 78, 453473. http://dx.doi.org/10.1016/00401951(81)90024-X.

Chopra, P.N., Paterson, M.S., 1984. The role of water in the deformation of dunite. J. Geophys. Res. 89, 7861-7876. http://dx.doi.org/10.1029/JB089iB09p07861.

Cooper, R.F., Kohlstedt, D.L., 1984. Solutionprecipitation enhanced diffusional creep of partially molten olivine-basalt aggregates during hot-pressing. Tectonophysics 107, 207-233. http://dx.doi.org/10.1016/0040-1951(84)90252$X$.

Cooper, R.F., Kohlstedt, D.L., 1986. Rheology and structure of olivine-basalt partial melts. J. Geophys. Res. 91, 9315. http://dx.doi.org/10.1029/JB091iB09p09315.

Cordier, P., Demouchy, S., Beausir, B., Taupin, V., Barou, F., Fressengeas, C., 2014. Disclinations provide the missing mechanism for deforming olivine-rich rocks in the mantle. Nature 507, 516. http://dx.doi.org/10.1038/nature13043.

Deer, W.A., Howie, R.A., Zussmann, J., 1997. Rock forming minerals: Orthosilicates. Vol. 1A Geological Society of London, London, p.187.

Demouchy, S., 2010. Diffusion of hydrogen in olivine grain boundaries and implications for the survival of water-rich zones in the Earth's mantle. Earth Planet. Sci. Lett. 295, 305-313. http://dx.doi.org/10.1016/j.epsl.2010.04.019.

Demouchy, S., Schneider, S.E., Mackwell, S.J., Zimmerman, M.E., Kohlstedt, D.L., 2009. Experimental deformation of olivine single crystals at lithospheric temperatures. Geophys. 
Res. Lett. 36, L04304.

http://dx.doi.org/10.1029/2008GL036611.

Demouchy, S., Tommasi, A., Barou, F., Mainprice, D., Cordier, P., 2012. Deformation of olivine in torsion under hydrous conditions. Phys. Earth Planet. Inter. 202-203, 56-70.

http://dx.doi.org/10.1016/j.pepi.2012.05.001.

Demouchy, S., Tommasi, A., Ballaran, T.B. \& Cordier, P., 2013. Low strength of Earth's uppermost mantle inferred from tri-axial deformation experiments on dry olivine crystals. Phys. Earth Plan. Inter., 220, 37-49.

Demouchy, S., Mussi, A., Barou, F., Tommasi, A., Cordier, P., 2014. Viscoplasticity of polycrystalline olivine experimentally deformed at high pressure and $900^{\circ} \mathrm{C}$. Tectonophysics 623, 123-135.

http://dx.doi.org/10.1016/j.tecto.2014.03.022.

Demouchy, S., Bolfan-Casanova, N., 2016. Distribution and transport of hydrogen in the lithospheric mantle: A review. Lithos. 240-243, 402-425. http://dx.doi.org/10.1016/j.lithos.2015.11.012.

Durham, W.B., 1975. Plastic flow of single-crystal olivine. Ph.D. Thesis, Dep. of Earth and Planet. Sci., Mass. Inst. of Technol., Cambridge, USA.

Durham, W.B., Goetze, C., Blake, B., 1977. Plastic flow of oriented single crystals of olivine. J. Geophys. Res. 82, 5755-5770.

Edmond, J.M., Paterson, M. S., 1972. Volume changes during the deformation of rocks at high pressure. Int. J. Rock Mech. and Mining Sci. 9, 161-182.

Estrin, Y., Tóth, L.S., Molinari, A., Bréchet, Y., 1998. A dislocation-based model for all hardening stages in large strain deformation. Acta Mater. 46, 5509-5522. http://dx.doi.org/10.1016/S13596454(98)00196-7.

Evans, B., Goetze, C., 1979. The temperature variation of hardness of olivine and its implication for polycrystalline yield stress. J. Geophys. Res. 84, 5505-5524.

Evans, B., Kohlstedt, D.L., 1995. Rheology of rocks. in: Ahrens, T. J. (ed.): Rock physics and phase relations: A handbook of physical constants, AGU Ref. Shelf 3, 148-165.

Farla, R.J.M., Kokkonen, H., Gerald, J.D.F., Barnhoorn, A., Faul, U.H., Jackson, I., 2011. Dislocation recovery in fine-grained polycrystalline olivine. Phys. Chem. Miner. 38, 363-377. http://dx.doi.org/10.1007/s00269-0100410-3.

Faul, U.H., Fitz Gerald, J.D., Farla, R.J.M., Ahlefeldt, R., Jackson, I., 2011. Dislocation creep of finegrained olivine. J. Geophys. Res. 116, B01203. http://dx.doi.org/10.1029/2009JB007174.

Faul, U.H., Cline, C. J. II, David, E. C., Berry A. J., Jackson, I., 2016. Titanium-hydroxyl defectcontrolled rheology of the Earth's upper mantle. Earth Planet. Sci. Lett., 452, 227-237.

Faul, U. H., Cline, C. J., Andrew, I. I., Ian, B., \& Gordana, J. (2017). Constraints on oxygen fugacity within metal capsules. Physics and Chemistry of Minerals. http://doi.org/10.1007/s00269-017-0937-7
Fei, H., Wiedenbeck, M., Yamazaki, D., Katsura, T., 2013. Small effect of water on upper-mantle rheology based on silicon self-diffusion coefficients. Nature 498, 213-215. http://dx.doi.org/10.1038/nature12193.

Frank, F. C., Read, Jr. W. T., 1950. Multiplication Processes for Slow Moving Dislocations. Phys. Rev. 79 (4): 722-723. doi:10.1103/PhysRev.79.722.

Frey, F.A., Prinz, M., 1978. Ultramafic inclusions from san carlos, Arizona: Petrologic and geochemical data bearing on their petrogenesis. Dev. Petrol. 5, 129-176. http://dx.doi.org/10.1016/B978-0444-41658-2.50013-4.

Friedel, G., 1922. The mesomorphic states of matter, in: Annales de Physique. 18, 273-474. http://dx.doi.org/10.1201/9780203022658.ch1b.

Frost, H.J. \& Ashby, M.F., 1982. Deformation mechanism maps: the plasticity and creep of metals and ceramics. Oxford: Pergamon Press.

Frost, D. J., \& Mccammon, C. A. (2008). The Redox State of Earth's Mantle. Annu. Rev. Earth Planet. Sci. 36, 389-420. http://doi.org/10.1146/annurev.earth.36.031207. 124322

Frank, F.C., 1958. I. Liquid crystals. On the theory of liquid crystals. Discuss. Faraday Soc. 25, 19. http://dx.doi.org/10.1039/df9582500019.

Girard, J., Chen, J., Raterron, P., \& Holyoke, C. W. (2013). Hydrolytic weakening of olivine at mantle pressure : Evidence of [100](010) slip system softening from single-crystal deformation experiments. Physics of the Earth and Planetary Interiors, 216, 12-20. http://dx.doi.org/10.1016/j.pepi.2012.10.009.

Goetze, C., 1978. Creep of engineering materials and of the Earth - The mechanisms of creep in olivine. Philos. Trans. R. Soc. London. A., 288, 99-119.

Goetze, C., Evans, B., 1979. Stress and temperature in the bending lithosphere as constrained by experimental rock mechanics. Geophys. J. R. Astron. Soc. 59, 463-478. http://dx.doi.org/10.1111/j.1365246X.1979.tb02567.x.

Gribb, T.T., Cooper, R.F., 1998. A high-temperature torsion apparatus for the high-resolution characterization of internal friction and creep in refractory metals and ceramics: Application to the seismic-frequency, dynamic response of Earth's upper mantle. Rev. Sci. Instrum. 69, 559-564. http://dx.doi.org/10.1063/1.1148694.

Griggs, D.T., Turner, F.J., Heard, H.C., 1960. Deformation of rocks at $500^{\circ}$ to $800^{\circ} \mathrm{C}$. GSA Mem. 79, 39-104. http://dx.doi.org/10.1130/MEM79.

Gueguen, Y., Nicolas, A., 1980. Deformation of mantle rocks. Annu. Rev. Earth Planet. Sci. 8, 119-144. http://dx.doi.org/10.1146/annurev.ea.08.050180. 001003.

Hansen, N., 2004. Hall-Petch relation and boundary strengthening, Scripta Mater. 51, 801806.doi:10.1016/j.scriptamat.2004.06.002

Hansen, L.N., Zimmerman, M.E., Kohlstedt, D.L., 2011. Grain boundary sliding in San Carlos 
olivine : Flow law parameters and crystallographic - preferred orientation 116, 116. http://dx.doi.org/10.1029/2011JB008220.

Hansen, L.N., Zimmerman, M.E., Dillman, A.M., Kohlstedt, D.L., 2012. Strain localization in olivine aggregates at high temperature: A laboratory comparison of constant-strain-rate and constant-stress boundary conditions. Earth Planet. Sci. Lett. 333-334, 134-145. http://dx.doi.org/10.1016/j.epsl.2012.04.016.

Hawkes, H.E.J., 1946. Olivine from northern California showing perfect cleavage. Am. Mineral. 31, 276-283.

Hielscher, R., Schaeben, H., 2008. A novel pole figure inversion method: Specification of the MTEX algorithm. J. Appl. Crystallogr. 41, 1024-1037. http://dx.doi.org/10.1107/S0021889808030112.

Hiraga, T., Miyazaki, T., Tasaka, M., Yoshida, H., 2011. Mantle superplasticity and its self-made demise. Nature, 468, 1091-1094.

Hirth, G., Kohlstedt, D.L., 1995. Experimental constraints on the dynamics of the partially molten upper mantle: Deformation in the diffusion creep regime. J. Geophys. Res. 100, 15441-15449. http://dx.doi.org/10.1029/94JB02128.

Hirth, G. \& Kohlstedt, D.L., 1996. Water in the oceanic upper mantle: implications for rheology, melt extraction and the evolution of the lithosphere. Earth Planet. Sci. Lett., 144, 93-108.

Hirth, G. \& Kohlstedt, D.L., 2003. Rheology of the upper mantle and the mantle wedge: a view from the experimentalists. In J. Eiler, ed. Inside the Subduction Factory. Washington, DC: American Geophysical Union. pp.83-105.

Hutchinson, J.W., 1977. Creep and plasticity of hexagonal polycrystals as related to single crystal slip. Metall. Trans. A 8, 1465-1469. http://dx.doi.org/10.1007/BF02642860.

Idrissi, H., Bollinger, C., Boioli, F., Schryvers, D., Cordier, P., 2016. Low-temperature plasticity of olivine revisited with in situ TEM nanomechanical testing. Sci. Adv. 2, e1501671. http://dx.doi.org/10.1126/sciadv.1501671.

Jung, H., Karato, S.-i., 2001. Water-induced fabric transitions in olivine. Science. 293, 1460-1463. http://dx.doi.org/10.1126/science.1062235.

Karato, S.-i., Paterson, M.S. \& Fitzgerald, J.D., 1986. Rheology of synthetic olivine aggregates: influence of grain size and water. J. Geophys. Res. 91, 8151-76.

Karato, S.-i., Wu, P., 1993. Rheology of the Upper Mantle: A synthesis. Science (80). 260, 771778. http://dx.doi.org/10.1126/science.260.5109.771.

Karato, S.-i., Riedel, M.R., Yuen, D.A., 2001. Rheological structure and deformation of subducted slabs in the mantle transition zone: Implications for mantle circulation and deep earthquakes. Phys. Earth Planet. Int. 127, 83108. http://dx.doi.org/10.1016/S00319201(01)00223-0.

Katayama, I., Jung, H., Karato, S.I., 2004. New type of olivine fabric from deformation experiments at modest water content and low stress. Geology
32, 1045-1048.

http://dx.doi.org/10.1130/G20805.1.

Keefner, J.W., Mackwell, S.J., Kohlstedt, D.L., Heidelbach, F., 2011. Dependence of dislocation creep of dunite on oxygen fugacity: Implications for viscosity variations in Earth's mantle. J. Geophys. Res. 116, 1-15. http://dx.doi.org/10.1029/2010JB007748.

Kirby, S.H., 1980. Tectonic stresses in the lithosphere: constraints provided by the experimental deformation of rocks. J. Geophys. Res. 85, 6353-6363. http://dx.doi.org/10.1029/JB085iB11p06353.

Kohlstedt, D. L., Zimmermann, M. E., 1996. Rheology of partially molten mantle rocks. Annu. Rev. Earth Planet. Sci., 24, 41-62.

Kuijper, R.P., 1979. Olivine with perfect cleavage. Neues Jahrb. Miner. Monatshefte 10-16.

Kuroda, Y., Shimoda, S., 1967. Olivine with welldeveloped cleavages: its geological and minerological meanings. J. Geol. Soc. Japan 73, 377-388. http://dx.doi.org/10.5575/geosoc.73.377.

Liu, W., Kung, J., Li, B., 2005. Elasticity of San Carlos olivine to $8 \mathrm{GPa}$ and $1073 \mathrm{~K}$, Geophys. Res. Lett., L16301, doi:10.1029/2005GL023453.

Louchet, F., Weiss, J., Richeton, T., 2006. Hall-Petch Law Revisited in Terms of Collective Dislocation Dynamics. Phys. Rev. Lett., 97, 075504.

Mackwell, S., 2008. Rheological consequences of redox state. Rev. Mineral. Geochemistry 68, 555-569. http://dx.doi.org/10.2138/rmg.2008.68.20.

Mackwell, S.J., Kohlstedt, D.L., Paterson, M.S., 1985. The role of water in the deformation of olivine single crystals. J. Geophys. Res. 90, 11319. http://dx.doi.org/10.1029/JB090iB13p11319.

Mainprice, D., Bachmann, F., Hielscher, R., Schaeben, H. (2014) Descriptive tools for the analysis of texture projects with large datasets using MTEX: strength, symmetry and components. In: Faulkner, D. R., Mariani, E. \& Mecklenburgh, J. (eds) Rock Deformation from Field, Experiments and Theory: A Volume in Honour of Ernie Rutter. Geological Society, London, Special Publications, 409, http://dx.doi.org/10.1144/SP409.8.

Mei, S., Kohlstedt, D., 2000a. Influence of water on plastic deformation of olivine aggregates 1 Diffusion creep regime. J. Geophys. Res. 105, 21457-21469.

Mei, S., Kohlstedt, D.L., 2000b. Influence of water on plastic deformation of olivine aggregates 2 . Dislocation creep regime. J. Geophys. Res. 105, 21471-21481.

Mei, S., Suzuki, A.M., Kohlstedt, D.L., Dixon, N.A., Durham, W.B., 2010. Experimental constraints on the strength of the lithospheric mantle. J. Geophys. Res. 115, 1-9. http://dx.doi.org/10.1029/2009JB006873.

Marquardt, K., Rohrer, G.S., Morales, L., Rybacki, E., Marquardt, H., Lin, B., 2015. The most frequent interfaces in olivine aggregates: the GBCD and its importance for grain boundary related 
processes. Contrib. Mineral. Petrol. 170, 40 http://dx.doi.org/10.1007/s00410-015-1193-9.

Mises, R. v., 1928. Mechanik der plastischen

Formänderung von Kristallen. Zeitschrift Angew. Math. Mech. 8, 161-185.

Miyazaki, T., Sueyoshi, K., Hiraga, T., 2013. Olivine crystals align during diffusion creep of Earth's upper mantle. Nature, 502, 321-326.

Moosbrugger, C., 2002. Representation of stressstrain behavior. In: Tamarin, Y. (ed) Atlas of Stress-Strain Curves, ASM Int., Materials Park, Ohio, $2^{\text {nd }}$ ed., 1-20

Morawiec, A., 2004. Orientations and rotations computations in crystallographic textures. Springer Berlin Heidelberg, Berlin. pp.200.

Mouthereau, F., Watts, A.W., Burov E., 2013. Structure of orogenic belts controlled by

lithosphere age. Nature Geosciences, 6, 785-789, doi: 10.1038/NGEO1902

Mussi, A., Cordier, P., Demouchy, S., Hue, B. 2017. Hardening mechanisms in olivine single crystal deformed at $1090^{\circ} \mathrm{C}$ : an electron tomography study. Phil. Mag., http://dx.doi.org/10.1080/14786435.2017.13678 58.

Nes, E., 1997. Modelling of work hardening and stress saturation in FCC metals. Prog. Mater. Sci. 41, 129-193. http://dx.doi.org/10.1016/S00796425(97)00032-7.

Nicolas, A., 1986. Structure and petrology of peridotites: Clues to their geodynamic environment. Rev. Geophys., 24, 875-895. http://dx.doi.org/10.1029/RG024i004p00875.

Nicolas, A., Boudier, F., Boullier, A. M., 1973. Mechanisms of flow in naturally and experimentally deformed peridotites. Am. J. Sci. 273, 853-876. http://dx.doi.org/10.2475/ajs.273.10.853.

Nicolas, A., Poirier, J.P., 1976. Crystalline plasticity and solid state flow in metamorphic rocks, selected topics in geological sciences series. London and New York, John Wiley \& Sons, 976 , p. 246.

Paterson, M.S., 1990. Rock deformation experimentation. Geophys. Monograph, 56, 187194.

Phakey, P., Dollinger, G., Christie, J., 1972. Transmission electron microscopy of experimentally deformed olivine crystals, in: Heard, H.C., Borg, I.Y., Carter, N.L., Raleigh, C.B. (Eds.), Flow and Fracture of Rocks. Geophys. Monogr. Ser., Washington, D.C., 16, 117-129.

Poirier, J.-P., 1975. On the slip systems of olivine. J. Geophys. Res. 80, 4059-4061. http://dx.doi.org/10.1029/JB080i029p04059.

Proietti, A., Bystricky, M., Guignard, J., Béjina, F., Crichton, W., 2016. Effect of pressure on the strength of olivine at room temperature. Phys. Earth Planet. Inter. 259, 34-44. http://dx.doi.org/10.1016/j.pepi.2016.08.004.

Quintanilla-Terminel, A., Zimmerman, M.E., Evans, B. and Kohlstedt, D.L. (2017) Microscale and nanoscale strain mapping techniques applied to creep of rocks. Solid Earth, 8, 751-765
Raleigh, C.B., 1965. Glide mechanisms in experimentally deformed minerals. Science 150 , 739-741. http://dx.doi.org/10.1126/science.150.3697.739.

Raleigh, C.B., 1967. Plastic deformation of upper mantle silicate minerals. Geophys. J. R. Astron. Soc. 14, 45-49. http://dx.doi.org/10.1111/j.1365246X.1967.tb06220.x.

Raleigh, C.B., 1968. Mechanisms of plastic deformation of olivine. J. Geophys. Res. 73, 5391. http://dx.doi.org/10.1029/JB073i016p05391.

Raterron, P., Wu, Y., Weidner, D.J., Chen, J., 2004. Low-temperature olivine rheology at high pressure. Phys. Earth Planet. Inter. 145, 149159. http://dx.doi.org/10.1016/j.pepi.2004.03.007.

Skemer, P., Warren, J.M., Hirth, G., 2012. The influence of deformation history on the interpretation of seismic anisotropy. Geochemistry, Geophys. Geosystems 13, Q03006. http://dx.doi.org/10.1029/2011GC003988.

Soustelle, V., Tommasi, A., Demouchy, S., Ionov, D.A., 2010. Deformation and fluid-rock interaction in the supra-subduction mantle: Microstructures and water contents in peridotite xenoliths from the Avacha volcano, Kamchatka. J. Petrol. 51, 363-394. http://dx.doi.org/10.1093/petrology/egp085.

Tommasi, A., Tikoff, B., Vauchez, A., 1999. Upper mantle tectonics: Three-dimensional deformation, olivine crystallographic fabrics and seismic properties. Earth Planet. Sci. Lett. 168, 173-186. http://dx.doi.org/10.1016/S0012821X(99)00046-1.

Tommasi, A., Vauchez, A., lonov, D.A., 2008. Deformation, static recrystallization, and reactive melt transport in shallow subcontinental mantle xenoliths (Tok Cenozoic volcanic field, SE Siberia). Earth Planet. Sci. Lett. 272, 65-77. http://dx.doi.org/10.1016/j.epsl.2008.04.020.

Tommasi, A., Baptiste, V., Vauchez, A., Holtzman, B., 2016. Deformation, annealing, reactive melt percolation, and seismic anisotropy in the lithospheric mantle beneath the southeastern Ethiopian rift: Constraints from mantle xenoliths from Mega. Tectonophysics 682, 186-205. http://dx.doi.org/10.1016/j.tecto.2016.05.027.

Tielke, J.A., Zimmerman, M.E., Kohlstedt, D.L., 2016. Direct shear of olivine single crystals. Earth Planet. Sci. Lett. 455, 140-148. http://dx.doi.org/10.1016/j.epsl.2016.09.002

Tielke, J.A., Zimmerman, M.E., Kohlstedt, D.L., 2017. Hydrolytic weakening in olivine single crystals. J. Geophys. Res. 122, 3465-3479. http://dx.doi.org/10.1002/2017JB014004

Turner, F.J., 1942. Preferred orientation of olivine crystals in peridotites, with special reference to New Zealand examples. Trans. R. Soc. New Zeal. 72, 280-300.

Underwood, E.E., 1970. Quantitative stereology. Reading, Mass., Addison-Wesley Pub. Co. p. 274. 
Velinskiy, V. V., Pinus, G. V., 1969. Olivines with perfect cleavages in ultrabasite of Chukotok. Docklady Academy of Sciences of the USSR Earth Science Sections ( English translation edition) 185, 99-101.

Wang, Q., 2016. Homologous temperature of olivine: Implications for creep of the upper mantle and fabric transitions in olivine. Sci. China Earth Sci. 59, 1138-1156. http://dx.doi.org/10.1007/s11430-016-5310-z.

Warren, J.M., Hirth, G., 2006. Grain size sensitive deformation mechanisms in naturally

deformed peridotites. Earth Planet. Sci. Lett., 248, 438-450.
Wenk, H.-R., Bennett, K., Canova, G.R., Molinari, A., 1991. Modelling plastic deformation of peridotite with the self-consistent theory. J. Geophys. Res. 96, 8337. http://dx.doi.org/10.1029/91JB00117. Young, C.I., 1969. Dislocations in the deformation of olivine. Am. J. Sci. 267, 841-852.

Zhang, S., Karato, S., 1995. Lattice preferred orientation of olivine aggregates deformed in simple shear. Nature 375, 774-777. 